Northwestern University School of Law

Northwestern University School of Law Scholarly Commons

Faculty Working Papers

2011

\title{
THE NEED FOR A RESEARCH CULTURE IN THE FORENSIC SCIENCES
}

Jonathan Koehler

Northwestern University School of Law, jay.koehler@northwestern.edu

Jennifer L. Mnookin

University of California, Los Angeles, School of Law

Simon A. Cole

Barry A.J. Fisher

Itiel E. Dror

See next page for additional authors

\section{Repository Citation}

Koehler, Jonathan; Mnookin, Jennifer L.; Cole, Simon A.; Fisher, Barry A.J.; Dror, Itiel E.; Houck, Max; Inman, Kieth; Kaye, David H.; Langenburg, Glenn; Risinger, D. Michel; Rudin, Norah; and Siegel, Jay, "THE NEED FOR A RESEARCH CULTURE IN THE FORENSIC SCIENCES" (2011). Faculty Working Papers. Paper 26.

http://scholarlycommons.law.northwestern.edu/facultyworkingpapers/26 


\section{Authors}

Jonathan Koehler, Jennifer L. Mnookin, Simon A. Cole, Barry A.J. Fisher, Itiel E. Dror, Max Houck, Kieth Inman, David H. Kaye, Glenn Langenburg, D. Michel Risinger, Norah Rudin, and Jay Siegel 


\title{
THE NEED FOR A RESEARCH CULTURE IN THE FORENSIC SCIENCES
}

\author{
Jennifer L. Mnookin, ${ }^{*}$ Simon A. Cole, Itiel E. Dror, \\ Barry A. J. Fisher, Max Houck, Keith Inman, David H. Kaye, \\ Jonathan J. Koehler, Glenn Langenburg, D. Michel Risinger, \\ Norah Rudin, Jay Siegel, and David A. Stoney
}

The methods, techniques, and reliability of the forensic sciences in general, and the pattern identification disciplines in particular, have faced significant scrutiny in recent years. Critics have attacked the scientific basis for the assumptions and claims made by forensic scientists both in and out of the courtroom. Defenders have emphasized courts' long-standing acceptance of forensic science evidence, the relative dearth of known errors, and the skill and experience of practitioners. This Article reflects an effort made by a diverse group of participants in these debates, including law professors, academics from several disciplines, and practicing forensic scientists, to find and explore common ground. To what extent do the forensic sciences need to change in order to place themselves on an appropriately secure foundation in the $21^{\text {st }}$ century? We all

\footnotetext{
* Jennifer L. Mnookin, Professor of Law, Founding Co-Director of the Program on Law, Science, and Evidence (PULSE), UCLA School of Law; Simon A. Cole, Associate Professor, Department of Criminology, Law \& Society, UC Irvine; Itiel E. Dror, Researcher, Institute of Cognitive Neuroscience, University College, London, and Principal Consultant, Cognitive Consultants International (CCI); Barry A. J. Fisher, Crime Laboratory Director (retired), Los Angeles County Sherriff's Department; Max M. Houck, Director, Forensic Science Initiative, Research Office, and Director, Forensic Business Research and Development, College of Business and Economics, West Virginia University; Keith Inman, Assistant Professor of Criminal Justice Administration, Cal State East Bay and Senior Criminalist, Forensic Analytical Sciences, Inc.; David H. Kaye, Distinguished Professor and Weiss Family Scholar, Dickinson School of Law, and Graduate Faculty, Forensic Science Program, Eberly College of Science, Penn State University; Jonathan J. Koehler, Beatrice Kuhn Professor of Law, Northwestern University School of Law; Glenn Langenburg, Forensic Scientist, Minnesota Bureau of Criminal Apprehension Forensic Science Services; D. Michael Risinger, John J. Gibbons Professor of Law, Seton Hall University School of Law; Norah Rudin, Forensic DNA Consultant; Jay Siegel, Chair, Department of Chemistry and Chemical Biology and Director, Forensic and Investigative Sciences Program, Indiana University-Purdue University; David A. Stoney, Chief Scientist, Stoney Forensic, Inc.

This Article grew out of a conference held at UCLA School of Law in February 2010 under the auspices of PULSE. We thank the UCLA School of Law and the A. Barry \& Lorri Cappello Fund for funding this event. We also thank Forrest Havens and Julie Nicholson for helpful research assistance. Special thanks to Jerry Kang for his extraordinary mindmapping of the authors' working session during the conference. We would also like to thank the additional participants in the PULSE symposium, as well as the thoughtful commentators who have responded to this Article in this issue.
} 
firmly agree that the traditional forensic sciences in general, and the pattern identification disciplines, such as fingerprint, firearm, tool mark and handwriting identification evidence in particular, do not currently possess - and absolutely must develop-a well-established scientific foundation. This can only be accomplished through the development of a research culture that permeates the entire field of forensic science. A research culture, we argue, must be grounded in the values of empiricism, transparency, and a commitment to an ongoing critical perspective. The forensic science disciplines need to substantially increase their commitment to evidence from empirical research as the basis for their conclusions. Sound research, rather than experience, training, and longstanding use, must become the central method by which assertions are justified. In this Article, we describe the underdeveloped research culture in the non-DNA forensic sciences, offer suggestions for how it might be improved, and explain why it matters.

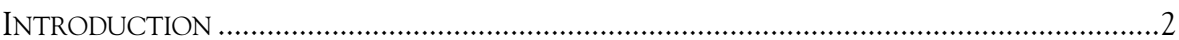

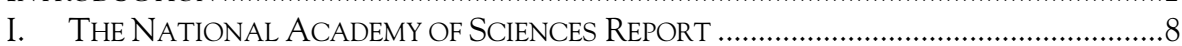

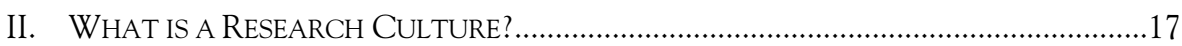

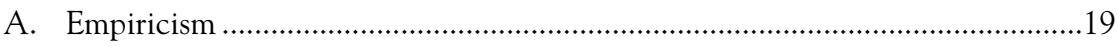

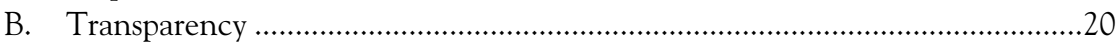

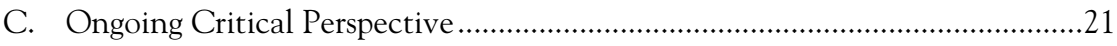

III. The Present LaCK OF A ReseArCh Culture In Forensic SCIENCE .....................22

IV. Creating a Research Culture: Some Possible Steps

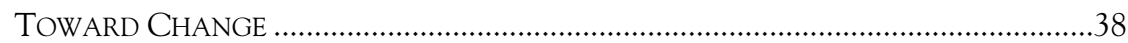

A. Increased Funding.......................................................................................40

B. Improving Forensic Education to Enhance a Research Culture …...................42

C. Improving the Culture of Forensic Science Journals ........................................47

D. Using Scientific Standards to Guide Casework ..............................................48

E. Enhancing the "Science" in the Scientific Working Groups (SWGs) .............50

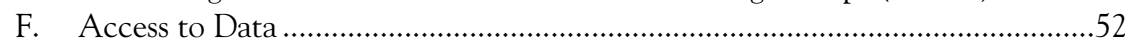

G. Managing the Tension Between an Adversarial Culture and a

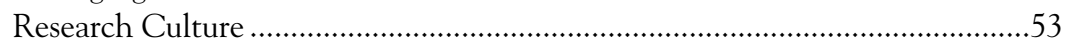

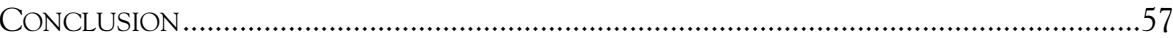

\section{INTRODUCTION}

Long-used types of forensic science-fingerprint examination, handwriting analysis, firearms and toolmark comparison, and other forms of pattern and impression evidence-are mainstays of criminal prosecution. For roughly a hundred years, these comparison and identification methods have regularly and routinely been employed as legal evidence. For most of that period, courts, attorneys, jurors, and the public, as well as forensic 
analysts themselves, have largely accepted this evidence as trustworthy and uncontroversial.

In the last few years, the situation has changed dramatically. These methods and techniques now face more criticism and scrutiny than ever before. Latent fingerprint identification, ${ }^{1}$ questioned document examination, and firearms comparison have been the targets of numerous admissibility challenges. Defendants have argued that this evidence is insufficiently valid to be admissible under Daubert v. Merrell Dow Pharmaceuticals, Inc., ${ }^{2}$ and insufficiently accepted by the relevant scientific community to be admissible under Frye v. United States. ${ }^{3}$ While most courts have continued to admit these forms of evidence, forensic practitioners have found themselves in the spotlight, forced to justify and defend practices that had previously evaded scrutiny. ${ }^{4}$ Meanwhile, scandals

1. A latent fingerprint is an impression left by a finger (or, more precisely, by friction ridge skin) on a surface. Latent prints are commonly recovered from crime scenes.

2. 509 U.S. 579 (1993). The Court, in an opinion by Justice Blackmun, held that the Federal Rules of Evidence required judges confronted with a challenge to scientific evidence to engage in a "flexible" inquiry whose "overarching subject is the scientific validity-and thus the evidentiary relevance and reliability — of the principles that underlie a proposed submission." Id. at 594-95. The Court elaborated on Daubert's approach in General Electric Co. v. Joiner, 522 U.S. 136 (1997), which reaffirmed the Court's commitment to trial court gatekeeping and made clear that the appellate standard for review of the trial court's admissibility decisions was abuse of discretion. In Kumho Tire Co. v. Carmichael, the Court held that the district court's gatekeeping obligations extended to all forms of expert evidence and that judicial evaluation of reliability of expert evidence should focus on the particular task at issue in the specific case rather than the general validity of a field of expertise writ large. 526 U.S. 137, 141 (1999).

3. 293 F. 1013 (D.C. Cir. 1923). Frye's key and oft-quoted language states:

Just when a scientific principle or discovery crosses the line between the experimental and demonstrable stages is difficult to define. Somewhere in this twilight zone the evidential force of the principle must be recognized, and while courts will go a long way in admitting expert testimony deduced from a well-recognized scientific principle or discovery, the thing from which the deduction is made must be sufficiently established to have gained general acceptance in the particular field in which it belongs.

Id. at 1014 (emphasis added). With any given forensic science, if the particular field, such as firearms comparison, is defined narrowly to consist only of firearms examiners, general acceptance cannot be in doubt. If the field is defined more broadly to include experts in all forms of pattern analysis, statisticians, and computer scientists, then the answer becomes less obvious. See, e.g., 1 DANIEL L. FAIGMAN ET AL., MODERN SCIENTIFIC EVIDENCE: THE LAW AND SCIENCE OF EXPERT TESTIMONY § 1:5, at 12-13 (2009-2010 ed.); DAVID H. KAYE, DAVID BERNSTEIN \& JENNIFER L. MNOOKIN: THE NEW WIGMORE: EXPERT EVIDENCE $§$ 6.3.3(b) (2d ed. forthcoming 2010); Simon A. Cole, Out of the Daubert Fire and Into the Fryeing Pan? Self-Validation, Meta-Expertise and the Admissibility of Latent Print Evidence in Frye Jurisdictions, 9 MINN. J. L. SCI. \& TECH. 453 (2008). In addition, many Frye states have inched towards a partial inquiry into validity. See 1 PAUL C. GIANNELli \& EDWARD J. IMWINKELREID, SCIENTIFIC EVIDENCE § 1.11, at 67 (2007); KAYE, BERNSTEIN \& MNOOKIN, supra, § 7.4.2(b).

4. For a recent look at the variety of judicial reactions to these forms of evidence, see generally, KAYE, BERNSTEIN \& MNOOKIN, supra note 3, § 15 (collecting cases); Jennifer L. Mnookin, The Courts, the NAS, and the Future of Forensic Science, 75 BROOK. L. REV. 
involving crime laboratories have rippled across the nation: from Los Angeles to Charlotte, from Oklahoma City to Houston, stories of carelessness, bias, incompetence, excessive coziness with prosecutors, and other embarrassing revelations have raised doubts about the trustworthiness and accuracy of some reported findings in a disturbing number of laboratories. ${ }^{5}$ In 2004, the American fingerprint community faced its most public fingerprint error ever when several highly experienced FBI examiners erroneously linked Oregon attorney (and Muslim convert) Brandon Mayfield to a fingerprint associated with the Madrid train bombing. ${ }^{6}$ One

(forthcoming 2010). Handwriting evidence has received a more ambivalent reception than fingerprint identification or firearms comparison. See D. Michael Risinger, Cases Involving the Reliability of Handwriting Identification Expertise Since the Decision in Daubert, 43 TULSA L. REV. 477 (2007).

5. Over the last twenty years, serious concerns have arisen in crime laboratories across the country, including in Boston, Chicago, Detroit, Houston, Los Angeles, New York, North Carolina, Oklahoma, San Francisco, and West Virginia, as well as at the FBI laboratory. KAYE, BERNSTEIN \& MNOOKIN, supra note 3, § 1.4.1(a). For examples from the voluminous press on these scandals, see JOHN F. Kelly \& PHILliP K. WeARnE, TAINTING EVIDENCE: INSIDE THE SCANDALS AT THE FBI CRIME LAB (1998); Tina Daunt, LAPD Blames Faulty Training in DNA Snafu, L.A. TIMES, July 31, 2002 (discussing the LAPD's accidental destruction of rape kits); Lianne Hart, DNA Lab's Woes Cast Doubt on 68 Prison Terms, L.A. TIMES, Mar. 31, 2003 (discussing the Houston crime lab scandal); Mandy Locke \& Joseph Neff, Inspectors Failed to Find SBI Faults, CHARlOTtes OBSERVER, Aug. 26, 2010; Moises Mendoza, HPD Fingerprinting Trouble Not Unique, HOUSTON CHRON., Dec. 132009 (giving context to Houston fingerprint lab problems); Steve Mills \& Maurice Possley, Report Alleges Crime Lab Fraud: Scientist Is Accused of Providing False Testimony, CHI. TRIB., Jan. 14, 2001 (discussing the Pamela Fish scandal in Chicago); Maggie Mulvihill \& Franci Richardson, Unfit Cops Put in Key Evidence Unit; Fingerprint Handlers Were All Thumbs, Boston HerAld, May 7, 2004; Maurice Possley, Steve Mills \& Flynn McRoberts, Scandal Touches Even Elite Labs: Flawed Work, Resistance to Scrutiny Seen Across U.S., CHI. TRIB., Oct. 21, 2004; Jonathan Saltzman \& John R. Ellement, Mass. DNA Lab's Lapses Draw Beacon Hill Inquiry: Delays, Errors Laid to Lack of Oversight, BOSTON GlOBE, Jan. 17, 2007 (discussing the Massachusetts state crime lab scandal); Ben Schmitt \& Joe Swickard, Troubled Detroit Police Crime Lab Shuttered: State Police Audit Results 'Appalling,' Wayne County Prosecutor Declares, Detroit FrEe PRESS, Sept. 26, 2008 (discussing the multiple problems that led to the Detroit crime lab's closure); Jaxon Van Derbeken, SFPD Drug-Test Technician Accused of Skimming, S.F. CHRON., Mar. 10, 2010 (discussing the San Francisco crime lab scandal); Murray Weiss, Criminal Errors, N.Y. POST, Dec. 4, 2007 (discussing a scandal at an NYPD crime lab); Jim Yardley, Inquiry Focuses on Scientist Employed by Prosecutors, N.Y. TIMES, May 2, 2001 (discussing the Joyce Gilchrist Oklahoma scandal); Court Invalidates a Decade of Blood Test Results in Criminal Cases, N.Y. Times, Nov. 12, 1993 (discussing the Fred Zain West Virginia scandal). The problems that have come to light have occurred in a variety of forensic areas, including serology, bloodstain pattern analysis, DNA, fingerprint identification and others. While our primary focus in this Article is on pattern evidence, these scandals serve as a reminder that the issues we describe warrant thoughtful attention throughout forensic science, not just in the pattern identification arena.

6. See Robert B. Stacey, Report on the Erroneous Fingerprint Individualization in the Madrid Train Bombing Case, 54 J FORENSIC IDENTIFICATION 706 (2004); OVERSIGHT AND REVIEW DIV., U.S. DEP'T OF JUSTICE, A REVIEW OF THE FBI'S HANDLING OF THE BRANDON MAYFIELD CASE (2006), available at http://www.usdoj.gov/oig/special/s0601/PDF_list.htm. 
study found that the trials of more than half of those defendants exonerated by post-conviction DNA testing included forensic evidence offered by the prosecution. $^{7}$ A follow-up study examining the underlying transcripts concluded that the testimony presented by forensic analysts had frequently been overstated or misleading. ${ }^{8}$ While currently available information does not permit quantification beyond the sample of case examined, these studies do suggest that misleading or erroneous forensic science has contributed to a substantial number of false convictions. A number of academics began to examine the research foundation of some long-used forensic disciplines and found that frequently made claims were supported by far less rigorous research than might have been expected. And in February 2009, the prestigious National Academy of Sciences (NAS) issued a long-awaited report on the forensic sciences that concluded: "With the exception of DNA analysis,... no forensic method has been rigorously shown to have the capacity to consistently, and with a high degree of certainty, demonstrate a connection between evidence and a specific individual or source."

The NAS Report suggested a number of major improvements for forensic science. Most significantly, it called for the creation of an entirely new, independent federal agency to oversee and regulate the practices of forensic science, and to ensure the development of rigorous research to

7. Brandon L. Garrett, Judging Innocence, 108 CoLUM. L. REV. 55, 82 (2008).

8. See Brandon L. Garrett \& Peter J. Neufeld, Invalid Forensic Science Testimony and Wrongful Convictions, 95 VA. L. REV. 1 (2009). There are three important caveats to be made regarding this article's conclusions. First, the single most problematic form of evidence in the Garrett \& Neufeld study was microscopic hair analysis, which is now typically used as an adjunct to mitochondrial DNA assessment of hair. Some have therefore argued that this makes the study's conclusions largely moot. See, e.g., JOHN COLlins \& JAY JARVIS, CRIME LAB RePORT, THE WRONGFUL CONVICTION OF FORENSIC SCIENCE (2008), available at http://www.crimelabreport.com/library/pdf/wrongful_conviction.pdf. However, there is no reason to believe that the culture that produced these frequent overstatements and failures to adhere strictly to conclusions warranted by the evidence was limited to microscopic hair analysis. Second, it is important to recognize that some of the expert testimony was not erroneous or overstated, even if it turned out to invite an incorrect inference about the identity of the perpetrator. See, e.g., COMM. ON IDENTIFYING THE NEEDS OF THE FORENSIC SCIS. CMTY., NAT'L RESEARCH COUNCIL, STRENGTHENING FORENSIC SCIENCE IN THE UNITED STATES: A PATH FORWARD 120 (2009) [hereinafter NAS REPORT] (pointing out that evidence such as physical inspection of hair or paint that merely identifies a trace as falling into a large class of potential sources is accurate even if it turns out that the defendant is not the source). Third, of course, we have virtually no direct information in these cases about how the jury perceived the forensic science evidence. It would therefore be dangerous to infer from the mere fact of conviction that the jury found the forensic science evidence either persuasive or critical in any given case; however, it would be equally questionable to presume that it did not. The prosecution proffered it, after all, to aid in conviction.

9. NAS REPORT, supra note 8 , at 7. 
determine the capabilities and the limits of forensic science. ${ }^{10}$ This combination of events-legal challenges, laboratory scandals, widely publicized errors, skeptical scholarship, and a highly critical national report-has focused sometimes unwelcome but badly needed attention on the forensic sciences. These developments offer the opportunity for reflection and improvement.

Now, roughly two years after the publication of this major report, where do the pattern and impression disciplines and the forensic sciences more generally stand? ${ }^{11}$ What are the ongoing problems in these fields? What ought to be the intellectually significant and yet practically realizable goals for improving forensic science evidence over the next decade or two? The purpose of this Article is to describe what we think forensic science most needs in order to best serve justice, the legal system, the public, and its own practitioners. Our central argument is that the pattern identification disciplines, and forensic science more generally, do not currently possessand absolutely must develop-an adequate research culture. In what follows, we will outline the essential elements of a research culture; provide examples to support our claim that within these disciplines such a culture is weak or faltering; and offer some concrete suggestions for how a research culture might be created.

The authors of this essay are a diverse group. This group includes those who are quite regularly labeled critics of forensic science, as well as defenders, including some who toil in the fields of forensic science every day. It includes forensic analysts from several fields who regularly appear in court testifying to the reliability of forensic evidence, as well as those who have appeared in court criticizing such evidence. Some of us are pursuing empirical research about forensic science; others write more conceptually

10. Id.

11. Our primary focus is on pattern and impression evidence. These disciplines include fingerprint analysis, firearms and toolmark comparison, questioned document examination, shoeprint examination, microscopic hair comparison, tire tread comparison, blood spatter analysis, bite mark analysis, and other physical object comparisons. These disciplines have in common that they attempt to determine whether or not a particular pattern or impression-be it a shoeprint, a tire tread, a fingerprint, or a bullet — can be associated with a particular source. (Blood spatter analysis is an exception, as it attempts to use the pattern of blood to infer something about the physical events that gave rise to them). Although we focus primarily on pattern evidence, many of our arguments apply to forensic science more broadly. Tracing out with specificity where they do and do not fully apply across the broader range of forensic sciencesfrom DNA analysis to arson investigation to toxicology - is beyond the scope of this Article. We recognize that different portions of the forensic science landscape vary in the extent to which they already possess a robust research culture, but we believe that the forensic science enterprise, as a whole, would benefit from more focused efforts to develop the outlook and practices referred to in this Article as a research culture. 
about its strengths and limitations; still others among us spend more time practicing forensic science than writing about it. One of us is a former director of a major crime laboratory. The academics in this group come from multiple fields and varying disciplinary backgrounds, including law, cognitive psychology, chemistry, molecular biology, forensic science, and the sociology of science. One member of the group was on the NAS committee and helped write its report.

Given the breadth of backgrounds, disciplines, and points of view, and given the current controversies surrounding forensic science, it will come as no surprise that this diverse group of authors does not agree about everything. We cannot pretend to share a wholly unified vision for the future of forensic science. But what is striking-and what generated this Article-is that there is a good deal about which we do agree. The purpose of this Article is to focus on these substantial areas of agreement. We aim to lay out our shared understanding of some of the current problems in forensic science, and our consensus on how to improve the pattern identification fields, and the rest of the forensic science enterprise, so that they will rest on an appropriately secure foundation as they continue to provide valuable evidence into the twenty-first century.

Significantly, despite our diverse backgrounds and points of view, we agree on many aspects of both the diagnosis of current difficulties and a direction for a cure. In our collective opinion, the pattern identification disciplines, as well as other forms of forensic science evidence, must be placed on a more rigorous scientific foundation. More generally, we believe that a significant culture shift is required: Forensic science needs to focus more on science than on law, to shift from a quasi-adversarial perspective to a research orientation. In short, we call for the development and instantiation of what we will term a research culture within forensic science. The emergence of a research culture would affect how evidence is understood, change analysts' relationship to empirical data, and alter how evidence is reported. We do not delude ourselves that change comes easily or that a culture shift alone will immediately ensure that all forensic analyses are well founded. ${ }^{12}$ But we believe that this transition is both necessary and, while difficult, genuinely feasible.

12. To be sure, scientists steeped in the research culture we describe in this Article also sometimes make claims that outstrip their data or promote methods before the application has been shown to be fully robust or before all its limitations are clear. See, e.g., DAVID H. KAYE, THE DOUBLE HELIX AND THE LAW OF EVIDENCE 51-53 (2010) (describing the early claims of the developer of DNA fingerprinting). Nevertheless, in a competitive research culture, any premature enthusiasm or dubious assertions are likely to be met with criticism from others in the community, 
In what follows, we begin with a brief overview of the NAS Report, a watershed publication for the assessment of the current state of the forensic sciences. We use this report as a springboard to describe our consensus about what the forensic sciences need most in order to attain a solid footing over the next decades: to wit, the creation of a robust research culture, in which empirical evidence and careful scrutiny regarding the evidentiary warrant for whatever claims are made become part of the ordinary way of thinking about forensic practices. In Part II, we describe what we see as the critical components of a research culture, including a focus on empirical evidence, transparency, and a consistently critical and reflective perspective on claims of knowledge. In Part III, we provide a number of examples and illustrations to show why we do not believe that the research culture within forensic sciences, and within pattern and impression evidence in particular, is presently either well developed or robust. In the final Part, we offer a variety of suggestions, some of them familiar and some of them more innovative, for creating and fostering a research culture for forensic science.

\section{The NATiOnAl ACADEMy OF SCIENCES Report}

In February 2009, The National Academy of Sciences issued its major report on forensic science. ${ }^{13}$ Congress commissioned the report late in 2005 at the behest of the forensic science community itself. The Academy appointed a panel of judges, scholars, and forensic and legal practitioners to write the report. This committee heard more than sixteen days of testimony-more than eighty witnesses in eight meetings over a two-year period-from a variety of leading forensic scientists and academic researchers. ${ }^{14}$

In addition to the major recommendation to create a National Institute of Forensic Science (NIFS), the committee put forward two other

leading in the long run to a much more secure foundation for the applications of the theory or procedure. See id. at 53-54, 117, 119-20, 123-26, 138 (describing how the scientists who promoted or defended DNA identification responded to various published criticisms); see also Jennifer L. Mnookin, People v. Castro: Challenging the Forensic Use of DNA Evidence, in EVIDENCE STORIES 207 (Richard Lempert ed., 2006). See generally D. Michael Risinger, The Irrelevance, and Central Relevance, of the Boundary Between Science and Non-Science in the Evaluation of Expert Witness Reliability, 52 VILL. L. REV. 679, 700-12 (2007).

13. NAS REPORT, supra note 8.

14. Harry T. Edwards, Co-Chair, Committee On Identifying the Needs of the Forensic Science Community, The National Academy of Sciences Report on Forensic Sciences: What It Means for the Bench and Bar (May 6, 2010). For a close look at the committee and who was on it, see D. Michael Risinger, The NAS/NRC Report on Forensic Science: A Path Forward Fraught with Pitfalls, 2010 UTAH L. REV. (forthcoming). 
important structural recommendations: the removal of public forensic science laboratories from administrative control of law enforcement agencies or prosecutor's offices; ${ }^{15}$ and the gradual abolition of state and local coroner's offices in favor of a medical examiner system. ${ }^{16}$ Given the committee's key finding that an inadequate research basis existed for claims often made in forensic science, most of the recommendations were concerned with improving the science in forensic science. Specific recommendations included calls for:

(1) Foundational research that would assess the validity and reliability of methods used in the analysis of evidence, especially pattern evidence. ${ }^{17}$

(2) Further research into the issues of cognitive bias and its effects on forensic decisionmaking. The committee recognized the significant need to investigate when contextual or confirmational bias might affect examiner's processes or their conclusions, and the need both to study its extent and to develop countermeasures. ${ }^{18}$

(3) Standardization of laboratory reports and a standard definition of terms, especially those expressing the association between an item of evidence and a possible source. $^{19}$

(4) Mandatory accreditation of all forensic science laboratories that process evidence for court and mandatory certification of all forensic scientists who analyze evidence. ${ }^{20}$

(5) A mandatory code of ethics that is tied to certification and makes possible the removal of serious ethical violators from the practice of forensic science. ${ }^{21}$

The NAS Committee was not charged specifically with examining the issues surrounding pattern and impression evidence, although the final report does emphasize these areas. This focus emerged as the committee heard testimony about the present state of research and the validity and reliability of forensic science methods. In testimony presented, various

\footnotetext{
15. NAS REPORT, supra note 8, at 23-24.

16. Id. at 29 .

17. Id. at $22-23$.

18. Id. at 24 .

19. Id. at 21 .

20. Id. at 25 .

21. Id. at 26 .
} 
types of pattern evidence were cited as poster children for the lack of scientific foundation in forensic science and the need for more research to establish the validity (or lack of it) in forensic science's analytical methods. ${ }^{22}$ Fairly or not, the report reflects this emphasis, and in this Article, we too focus primarily on the pattern and impression areas. Nevertheless, it is important to recognize that the pattern evidence areas are not alone in generating the concerns expressed in the NAS Report or in this Article. Every area of forensic science, including DNA typing, described by the NAS Committee as the "gold standard" of forensic science, suffers to some degree from the problems the Report ascribed to pattern evidence. Most of the recommendations in the NAS Report are global in their reach; they are intended to apply to forensic science as a whole. Similarly, although we focus on pattern and impression evidence processed by human analysts using visual examination, many of our arguments apply beyond these domains. At the same time, we recognize that forensic science culture is not monolithic or unitary. We hope that our remarks in the context of pattern and impression evidence will encourage further discussion and attention to the question of how to create, develop, or improve the research culture in other areas, including forensic chemistry, DNA analysis, fire investigation, and medicolegal death investigation.

We all agree that publication of the Report was a watershed moment for the forensic sciences. The Report continues to generate both attention and controversy. Already it has prompted, or at least spurred, some degree of change in forensic science practice. ${ }^{23}$ It continues to influence practicing forensic scientists themselves, as well as those who interact with forensic disciplines, including lawyers and judges, government officials, and government regulatory and funding entities such as the National Institute of Justice (NIJ), National Institute of Standards and Technology (NIST), and the National Science Foundation (NSF). ${ }^{24}$

22. Chapter five of the NAS Report discusses and offers summary assessments of, for example, biological evidence, analysis of controlled substances, friction ridge analysis, shoeprints and tire tracks, toolmark and firearms identification, hair and fiber evidence, questioned document examination, paint and coating evidence, arson and explosives evidence, bitemark analysis, and bloodstain pattern analysis. See id. at 127-83. Chapter nine focuses entirely on medicolegal death analysis. See id. at 241-68.

23. See, e.g., IAI Resolution 2010-18 (July 16, 2010) (reflecting a "change [in] the official position of the Association related to Friction Ridge Examinations based on advances in the science and scientific research").

24. The National Science Foundation recently funded a workshop at Northwestern Law School called "Cognitive Bias and Forensic Science" largely designed to encourage social and cognitive psychologists to conduct empirical studies to improve our understanding of factors that affect forensic science judgments and decisions. Similarly, the National Institute of Justice has 
We also agree with much of the content of the Report. ${ }^{25}$ Perhaps most significantly, we agree with the National Academy's central and important conclusion that the traditional forensic sciences are, at this point, inadequately supported by empirical data that would justify the strong claims analysts frequently make. We believe that numerous assertions made both in routine practice and in court are neither backed up by sufficient empirical data or research, nor are the kinds of claims that can be justified or validated simply by reference to longstanding experience. ${ }^{26}$ We have in mind, for example, asserting an error rate of zero for the methodology of latent fingerprint identification; testifying that forensic practitioners have an adequate empirical and experiential basis for confidently determining in run-of-the-mill cases that two prints-or shoe marks or firearms or exemplars of handwriting - share a common source to the exclusion of all other possible sources; ${ }^{27}$ claiming confidence based on experience that

solicited research proposals from social scientists to study, for example, “'context bias' and the need for a greater understanding of the scope of this issue in forensic laboratories." NAT'L INST. of Justice, U.S. Dep’t of Justice, Solicitation: Social SCIENCE RESEARCh in ForensiC SCIENCE 3 (2010).

25. One author of this Article served on the NAS committee, and several others gave invited presentations to the committee. Nonetheless, we do not agree with every sentence or every detail of every argument in this report. Certainly we each have both nits to pick as well as admiration for its strengths; indeed several of us have already expressed both our criticism and our praise in print. See, e.g., Simon A. Cole, Who Speaks for Science? A Response to the National Academy of Sciences Report on Forensic Science, 9 LAW, PROBABILITY \& RISK 25 (2010); Itiel E. Dror, How Can Francis Bacon Help Forensic Science? The Four Idols of Human Biases, 50 JURIMETRICS J. 93 (2009); David H. Kaye, The Good, the Bad, and the Ugly: The NRC Report on Strengthening Forensic Science in America, 50 SCI. \& JUST. 8 (2010); Jonathan J. Koehler, Forensic Science Reform in the 21st Century: A Major Conference, a Blockbuster Report and Reasons to Be Pessimistic, 9 LAW, PROBABILITY \& RISK 1 (2010); Mnookin, supra note 4; D. Michael Risinger, The NAS/NRC Report on Forensic Science: A Glass Nine-Tenths Full (This Is About the Other Tenth), 50 JURIMETRICS J. 21 (2009); Risinger, supra note 14. For a collection of responses from the forensic science community, see id. at

26. See, e.g., Mark A. Acree, What Is Science? The Dilemma of Fingerprint Science Revisited, 14 PRINT 4 (1998); Michelle Reznicek et al., ACE-V and the Scientific Method, 60 J. ForENSIC IDENTIFICATION 87 (2010); Michele Triplett \& Lauren Cooney, The Etiology of ACE-V and Its Proper Use: An Exploration of the Relationship Between ACE-V and the Scientific Method of Hypothesis Testing, 56 J. FORENSIC IDENTIFICATION 345 (2006); Norah Rudin \& Keith Inman, The Experience Fallacy, CACNEWS, Fourth Quarter 2010, at 10, available at http://cacnews.org/news/4thq10.pdf.

27. There may be rare instances when the strong claim of individualization could be warranted because both sides agree that the universe of potential suspects is small-such as, for example, in a situation where it is uncontested that a murder was committed by one of a small group of people in a locked house. But this inference is warranted in these circumstances because of the reduced size of the possible suspect population, not because of the prints' power to individualize to the exclusion of all others in the universe. See KAYE, BERNSTEIN \& MNOOKIN, supra note 3, § 15.2; David H. Kaye, Probability, Individualization, and Uniqueness in Forensic Evidence: Listening to the Academics, 75 BROOK. L. REV. 1163, 1174-75 (2010) (arguing that 
analysts have taken adequate steps to counter the effects of bias and context; or averring that the techniques used by forensic pattern disciplines follow "the scientific method." 28

We do recognize that experience, training, and longstanding investigatory and legal use can be sources of legitimate knowledge for pattern identification analysts. We also recognize that experience and training can give examiners, from a subjective point of view, sincere and deeply held confidence about their ability to do what they claim to do. But we do not believe that experience and training alone can validate universalist claims, such as the claim that latent fingerprint identification experts can individualize the source of a print to the exclusion of all other possibilities, ${ }^{29}$ or the claim that document examiners' experience enables them to assess the entire range of differences between two handwriting exemplars that can still be consistent with authorship by the same hand. ${ }^{30}$

testing most, but not all, of a closed set of suspects can justify the conclusion that the trace evidence originated from a single individual).

28. To some extent, these specific rhetorical claims are being modified in the aftermath of, and in response to, the Report. Indeed, the day after the Report was issued, the president of the International Association of Identification (IAI) wrote the membership: "It is suggested that members not assert $100 \%$ infallibility (zero error rate) when addressing the reliability of fingerprint comparisons." Memorandum From Robert Garrett, President, Int'l Ass'n for Identification, to the Membership of Int'l Ass'n for Identification (Feb. 19, 2009), available at http://www.theiai.org/current_affairs/nas_memo_20090219.pdf. In July, 2010, the IAI also opened the door to probabilistic testimony regarding the likelihood of a fingerprint match, and rescinded a 1979 resolution that limited such testimony to only three possible conclusions: individualization, exclusion, and unknown. For the recent resolution, see IAI Resolution 2010 18, supra note 23. In the summer of 2010, the chairman of the Scientific Working Group on Friction Ridge Analysis, Study and Technology (SWGFAST), a standard-setting organization for friction ridge analysis, issued a "clarification" asserting that the phrase "to the exclusion of all others" is likely to be removed from its Friction Ridge Examination Methodology materials. Letter From Leonard G. Butt, Chairman, Scientific Working Group on Friction Ridge Analysis, Study, and Tech., to Whom It May Concern (June 29, 2010), available at http://www.swgfast.org/Comments-Positions/SWGFAST_NAS_Position_Clarification.doc.

While we believe that all of these terminological shifts are positive developments, they do not negate or eliminate our more general arguments about the continued lack of a research culture in much of the pattern identification sciences, nor do they solve the problem of how to responsibly characterize the probative value of the results of an analysis. On this latter difficulty, see generally KAYE, BERNSTEIN \& MNOOKIN, supra note 3, § 15; Mnookin, supra note 4.

29. For discussion of the dubious underpinnings of assertions of "global individualization," see KAYE, BERNSTEIN \& MNOOKIN, supra note 3.

30. See, e.g., What Is Forensic Document Examination?: Handwriting Examination, SE. ASs'N OF FORENSIC DOCUMENT EXAMINERS, http://www.safde.org/whatwedo.htm (last visited Dec. 26, 2010):

Handwriting identification is based on the principle that, while handwriting within a language tends to be alike to the degree that we can meaningfully read it, there are individual features that distinguish one person's writing from that of another. Just as no two people are exactly alike, the handwritings of no two people are exactly alike in their 
More generally, we believe that not enough is yet known about a significant range of important questions. Consider, for example, the following: Precisely what are the capabilities and limitations of any particular pattern discipline? How often do pattern identification analysts make mistakes? When these errors occur, what causes them? How should error be defined, ${ }^{31}$ and what circumstances tend to increase the risk of error? How prevalent is the effect of cognitive bias on the activity of forensic examiners? When might access to contextual information affect forensic examiners' cognitive processes, or even their final determinations? How frequently might a portion of two fingerprints-or striation marks on bullets, or toolmarks, or handwriting specimens-share any given degree of similarity even if they derive from different sources? How does the use of large databases or new imaging technologies help these disciplines, and what dangers may new technologies pose? Just how much visual information is sufficient to undertake an accurate analysis of a handwriting specimen, a latent fingerprint, or a firearm? To what extent does training improve examiner accuracy? What kind of training is most effective?

The honest response to all of these questions is that we do not yet know. Suggestive research is emerging in some of these areas, including contributions from several co-authors of this Article. ${ }^{32}$ But we all agree that

combination of characteristics. There are, of course, natural variations within the handwriting of each individual. These variations must be closely and carefully studied by the examiner, so that he can distinguish between what is a "variation" and what is a "difference."

The examiner must also be cognizant of the differences between "class characteristics" and "individual characteristics." Class characteristics are those which are common to a group such as a particular writing system, family grouping, foreign language system, or professional group. Individual characteristics are those which are personal or peculiar letters or letter combinations, which, taken together, would not occur in the writing of another person.

31. See generally id. § 7.3.2(c); D. Michael Risinger, Whose Fault?: Daubert, the NAS Report and the Notion of Error in Forensic Science, FORDHAM URB. L.J. (forthcoming 2011).

32. See, e.g., Jan Beck, Sources of Error in Forensic Handwriting Evaluation, 40 J. FORENSIC SCI. 78 (1995); Silvia Bozza et al., Probabilistic Evaluation of Handwriting Evidence: Likelihood Ratio for Authorship, 57 J. Royal Stat. Soc'y Series C: Applied Stat. 329 (2008); Stephen G. Bunch, Consecutive Matching Striation Criteria: A General Critique, 45 J. FoRENSIC SCI. 955 (2000); Christopher Champed, Edmond Locard - Numerical Standards $\mathcal{B}$ "Probable" Identifications, $45 \mathrm{~J}$. FORENSIC IDENTIFICATION 136 (1995); Christophe Champod et al, Establishing the Most Appropriate Databases for Addressing Source Level Propositions, 44 SCI. \& JUST. 153 (2004); Itiel E. Dror et al., Contextual Information Renders Experts Vulnerable to Making Erroneous Identifications, 156 FORENSIC SCI. INT'L 74 (2006); Itiel E. Dror \& Robert Rosenthal, Meta-analytically Quantifying the Reliability and Biasability of Forensic Experts, 53 J. FORENSIC SCI. 900 (2008); Itiel E. Dror \& David Charlton, Why Experts Make Errors, 56 J. FORENSIC IDENTIFICATION 600 (2006); Adrian G. Dyer et al., An Insight Into Forensic Document Examiner Expertise for Discriminating Between Forged and Disguised Signatures, 53 J. ForENSIC SCI. 1154 (2008); Bryan Found \& Doug 
as of yet, the research basis that would permit a satisfying scientific answer to any of the above questions does not exist.

To be sure, we also recognize that the absence of evidence is not necessarily evidence of absence. ${ }^{33}$ Until recently, virtually no institutionnot the courts, not government funding agencies, very few research organizations or forensic science laboratories-was investing a great deal of time, energy, or resources into answering these questions. ${ }^{34}$ We therefore lack any major body of published scientific research directed at empirically

Rogers, The Probative Character of Forensic Handwriting Examiners' Identification and Elimination Opinions on Questioned Signatures, 178 FORENSIC SCI. INT'L 54 (2008); Moshe Kam et al., Signature Authentication by Forensic Document Examiners, 46 J. FORENSIC SCI. 884 (2001); Moshe Kam \& Erwei Lin, Writer Identification Using Hand-Printed and Non-Hand-Printed Questioned Documents, 48 J. FORENSIC SCI. 1391 (2003); Glenn Langenburg, A Performance Study of the ACEV Process: A Pilot Study to Measure the Accuracy, Precision, Reproducibility, Repeatability, and Biasability of Conclusion Resulting From the ACE-V Process, 59 J. FORENSIC IDENTIFICATION 219 (2009); Glenn Langenburg et al., Testing for Potential Contextual Bias Effects During the Verification Stage of the ACE-V Methodology When Conducting Fingerprint Comparisons, 54 J. FORENSIC SCI. 571 (2009); D. Meuwly, Forensic Individualisation From Biometric Data, 46 SCI. \& JUST. 205 (2006); Cedric Neumann et al., Computation of Likelihood Ratios in Fingerprint Identification for Configurations of Any Number of Minutiæ, 52 J. FORENSIC SCI. 54 (2007); Beatrice Schiffer \& Christophe Champod, The Potential (Negative) Influence of Observational Biases at the Analysis Stage of Fingermark Individualisation, 167 FORENSIC SCI. INT'L 116 (2007); Sargur N. Srihari et al., Discriminability of Fingerprints of Twins, 58 J. FORENSIC IDENTIFICATION 109 (2008); Sargur N. Srihari et al., Individuality of Handwriting, 47 J. FORENSIC SCI. 856 (2002); Kasey Wertheim et al., A Report of Latent Print Examiner Accuracy During Comparison Training Exercises, 56 J. FORENSIC IDENTIFICATION 55 (2006); Steve Gutowski, Error Rates in Fingerprint Examination: The View in 2006, FORENSIC BUll.,(Nat'l Inst. of Forensic Sci., Austl) Autumn 2006, at 18. This list is not exhaustive and should not be considered an endorsement of particular studies. While some of the research listed above is first rate, other studies may have significant flaws. But these works do at least constitute efforts to examine empirically relevant questions that have often been assumed rather than investigated.

33. Carl Sagan appears to have originated the felicitous phrasing "absence of evidence is not evidence of absence." CARL SAGAN, THE DEMON-HAUNTED WORLD: SCIENCE AS A CANDLE IN THE DARK 213 (1996). The difficulty with this aphorism is that the absence of evidence supporting a theory following a search for it can be evidence of the falsity of the theory. Cf. Elliott Sober, Absence of Evidence and Evidence of Absence: Evidential Transitivity in Connection With Fossils, Fishing, Fine-tuning, and Firing Squads, 143 PHIL. STUD. 63 (2009). However, read in context, Sagan was criticizing as "impatience with ambiguity" both the notion that whatever has not been proved false must be true and the opposite, that what has not been proved true must be false. SAGAN, supra, at 213. Inferring validity from the fact that many kinds of forensic science have not been proved invalid, and inferring invalidity from the lack of scientific proof of validity are both dangers to avoid.

34. There have been, to be sure, individuals engaged in some degree of research. See supra note 32. At the institutional level, there are also limited exceptions to these generalizations: the present research efforts emerging from the University of Lausanne and the period at the University of California-Berkeley in which several students under the tutelage of chemist and forensic scientist Paul Kirk pursued fundamental research in forensics are perhaps the most notable. On the current research program at Lausanne, see, for example, School of Criminal Justice (ESC), UNIVERSITÉ DE LAUSANNE, http://www.unil.ch/central/page2904_en.html (last visited Oct. 29, 2010). 
validating the conceptual claims and underpinnings of the pattern identification forensic disciplines. ${ }^{35}$ As a body of research continues to emerge, and we learn more about the frequency and types of errors that do occur, we may well find that many current practices turn out to have tolerably low error rates. As we develop and validate methods for probabilistic assessments of fingerprints, documents, or firearms, we may learn that in many circumstances the chances of a coincidental match are extremely remote, and we will certainly learn more about how common or remote they truly are. It could turn out that analysts' experience-based intuitive judgments about the correspondence sufficient to declare a match, even if not presently quantified or formally specified, are generally quite accurate. It may be that the biasing effects of access to contextual information extraneous to the forensic analysis rarely impact an examiner's conclusion or ultimate judgment when the information contained within the pattern is otherwise sufficiently clear.

All of this is possible. But none of it is yet adequately established. While our collective hunches about what the expanding pool of research will reveal vary, we all expect that additional, high-quality research will confirm that many forensic science techniques, including many kinds of pattern and impression evidence, do have a considerable degree of discriminatory power; and that there exists significant variation in discriminatory power across fields and within any given field, depending upon particularized circumstances. ${ }^{36}$ Furthermore, we all agree that we

35. NAS REPORT, supra note 8, at 107-08 ("Much forensic evidence-including, for example, bite marks and firearm and toolmark identifications-is introduced in criminal trials without any meaningful scientific validation, determination of error rates, or reliability testing to explain the limits of the discipline"). There are, to be sure, a handful of researchers beginning to change this, but a substantial body of work points out the absence of an adequate scientific foundation or empirical basis for the forensic sciences. See, e.g., SIMON A. COLE, SUSPECT IDENTITIES: A HISTORY OF FINGERPRINTING AND CRIMINAL IDENTIFICATION (2001); Simon A. Cole, Is Fingerprint Identification Valid? Rhetorics of Reliability in Fingerprint Proponents' Discourse, 28 LAW \& POL'Y 109 (2006); David L. Faigman, Anecdotal Forensics, Phrenology, and Other Abject Lessons From the History of Science, 59 HASTINGS L. J. 979 (2008); Jennifer L. Mnookin, Fingerprint Evidence in an Age of DNA Profiling, 67 BROOK. L. REV. 13 (2001) [hereinafter Mnookin, Fingerprint Evidence]; Jennifer L. Mnookin, The Validity of Latent Fingerprint Identification: Confessions of a Fingerprinting Moderate, 7 LAW, PROBABILITY \& RISK 127 (2008) [hereinafter Mnookin, Confessions]; D. Michael Risinger et al., Exorcism of Ignorance as a Proxy for Rational Knowledge: The Lessons of Handwriting Identification "Expertise," 137 U. PA. L. REV. 731 (1989); Michael J. Saks, The Legal and Scientific Evaluation of Forensic Science (Especially Fingerprint Expert Testimony), 33 SETON Hall L. REV. 1167, 1186-87 (2003); David A. Stoney, Measurement of Fingerprint Individuality, in ADVANCES IN FINGERPRINT TECHNOLOGY 327, 329 (Henry C. Lee \& R.E. Gaensslen eds., 2 d ed. 2001).

36. We all would predict, for example, that latent fingerprint identification will turn out to have a good deal more discriminatory power across a broader range of circumstances than forensic 
presently lack sufficient knowledge regarding the precise extent of this power or its limits.

Calling, therefore, for more research into these important questions, is both obvious and necessary. Here, again, we largely agree with the NAS Report's conclusion:

In most areas of forensic science, no well-defined system exists for determining error rates, and proficiency testing shows that some examiners perform poorly....

In most forensic science disciplines, no studies have been conducted of large populations to establish the uniqueness of marks or features. Yet, despite the lack of a statistical foundation, examiners make probabilistic claims based on their experience. A statistical framework that allows quantification of these claims is greatly needed. These disciplines also critically need to standardize and clarify the terminology used in reporting and testifying about the results and in providing more information.

Little rigorous research has been done to validate the basic premises and techniques in a number of forensic science disciplines. The committee sees no evident reason why conducting such research is not feasible.... ${ }^{37}$

To be sure, calling for more research is hardly a radical or controversial suggestion. Indeed, in the aftermath of the NAS Report, calls for more research have been widespread. Despite the Report's contentious reception, and notwithstanding the significant disagreements within forensic science, we cannot actually point to anyone who has argued that more research, in the abstract, is a bad idea. We have certainly heard it said that more research is not needed for basic validation. ${ }^{38}$ We have heard it said that the

odontology (bitemark analysis). On bitemarks, see Mary A. Bush et al., Statistical Evidence for the Similarity of the Human Dentition, 56 J. FoRENSIC SCI. (forthcoming 2011); D. Michael Risinger, Navigating Expert Reliability: Are Criminal Standards of Certainty Being Left on the Dock?, 64 ALB. L. REV. 99 (2000); Michael J. Saks, Merlin Eु Solomon: Lessons From the Law's Formative Encounters With Forensic Identification Science, 49 Hastings L. J. 1069 (1998). On the need to focus on the particularized task at hand rather than making global, field-wide admissibility judgments, see generally, D. Michael Risinger, Defining the "Task at Hand": Non-Science Forensic Science After Kumho Tire v. Carmichael, 57 WASH. \& LEE L. REV. 767 (2000).

37. NAS REPORT, supra 8, at 188-89.

38. See The AFTE Comm. for the Advancement of the Sci. of Firearm and Tool Mark Identification, The Response of the Association of Firearm and Tool Mark Examiners to the February 2009 National Academy of Science Report "Strengthening Forensic Science in the United States: A Path Forward", 41 AFTE J. 204, 205 (2009) ("There is an extensive body of research, extending back over one hundred years, which establishes the accuracy, reliability, and validity of conclusions rendered in the field of firearm and toolmark identification."); Jeffrey G. Barnes, History, in THE
FINGERPRINT
SOURCEBOOK
$1-17$
(2010),
available
at 
costs of research need to be balanced against other needs. And we have heard it said that forensic science laboratories are too busy to undertake, or even participate, in research. While not everyone views more research as imperative, we are not aware of anyone who, in print, or even in the hallways of conferences or crime labs, opposes the very idea of research in the abstract.

But "more research," imprecisely defined, is not enough. What forensic science needs is the creation and institutionalization of a research culture.

\section{WhAT IS A RESEARCH CULTURE?}

What do we mean by a research culture? Put simply, we mean a culture in which the question of the relationship between research-based knowledge and laboratory practices is both foregrounded and central. We mean a culture in which the following questions are primary: What do we know? How do we know that? How sure are we about that? We mean a culture in which these questions are answered by reference to data, to published studies, and to publically accessible materials, rather than primarily by reference to experience or craft knowledge, or simply assumed to be true because they have long been assumed to be true.

Before elaborating on the meaning of a research culture-and before presenting examples of the absence of a deep and robust research culture within forensic science together with suggestions for how to build it-it is critical to make one point: While we firmly believe that a research culture needs to become both more central and more entrenched within forensic science more generally, and within the pattern and impression disciplines specifically, this does not-and should not-mean that all forensic practitioners should henceforth be doing research. To the contrary. Even

http://www.ncjrs.gov/pdffiles1/nij/225321.pdf ("Study, research, and experimentation have led to and supported fingerprints as a means of individualization and a forensic tool of incalculable value. The research and practical knowledge accumulated over the course of many centuries well support the science."); Memorandum From Robert J. Garrett, President, Int'l Ass'n for Identification (IAI), to Members, IAI (Feb. http://www.theiai.org/current_affairs/nas_memo_20090219.pdf ("There is no research to suggest that properly trained and professionally guided examiners cannot reliably identify whole or partial fingerprint impressions to the person from whom they originated."); SWGGUN Systemic Requirements/Recommendations for the Forensic Firearm and Toolmark Laboratory, SCIENTIFIC WORKING GROUP FOR FIREARMS \& http://www.swggun.org/guidelinedocs/SWGGUN\%20Systemic\%20Requirements.pdf (last modified Apr. 23, 2010) ("The reliability of the science has been demonstrated and supported through proficiency tests and validity studies over many decades."). 
with a research culture in place, most forensic practitioners will continue simply to practice forensic science. Some forensic practitioners might be "test subjects" for researchers-the objects of research study to help achieve a better understanding of the strengths and limitations of their methods and techniques. They might sometimes partner with researchers to develop projects, or to evaluate the practical feasibility of a given research design; on other occasions, they might assess what research needs they deem especially significant. But even these practitioners need not, and indeed often should not, be the primary producers of the research themselves. ${ }^{39}$

Medicine provides an instructive analogy. Modern medicine is a product of both craft knowledge and structured research. Whether medicine incorporates more of a research culture than forensic science is perhaps debatable, but certainly evidence-based medicine coexists with a more experience-based, clinical practice orientation still widely influential among doctors. ${ }^{40}$ The point for our purposes, however, is that many more physicians make use of research than produce it. Some physicians certainly do pursue research alongside clinical practice, ${ }^{41}$ but large numbers of physicians make regular use of empirical research in selecting their diagnoses and treatment regimes without participating in its production. Their training may enable them to be intelligent consumers of medical research, but this does not mean they have the skills or the motivation to conduct it on their own.

Similarly, our hope for a more robust research culture in forensic science would not turn every forensic scientist into a scientific researcher. Some practicing forensic scientists would no doubt participate in

39. On the ways that forensic scientists may feel "role ambiguity" that makes them uncomfortable with the idea of being research subjects, see Simon A. Cole, Comment on 'Scientific Validation of Fingerprint Evidence Under Daubert', 7 LAW, PROBABILITY \& RISK 119, 122 (2008).

40. See Simon A. Cole, Toward Evidence-Based Evidence: Supporting Forensic Knowledge Claims in the Post-Daubert Era, 43 TULSA L. REV. 263 (2007). On evidence-based medicine, see, for example, DAVID L. SACKETT ET AL., EVIDENCE-BASED MEDICINE: HOW TO PRACTICE \& TEACH EBM (1997); William A. Silverman, WHERE'S THE EVIDENCE? DEBATES IN MODERN Medicine (1998); Stefan Timmermans \& Marc Berg, THE Gold Standard: The CHALlENGE OF EVIDENCE-BASED MEDiCINE AND STANDARDiZATION IN HEALTH CARE (2003); Evidence-Based Medicine Working Group, Evidence-Based Medicine-A New Approach to Teaching the Practice of Medicine, 268 JAMA 2420 (1992); David L. Sackett et al., Evidence-Based Medicine: What It Is and What It Isn't, 312 BRIT. MED. J. 71 (1996); Stefan Timmermans \& Aaron Mauck, The Promise and Pitfalls of Evidence Based Medicine, 24 HEALTH AfF. 18 (2005). For a classic reflection on the sometimes strained relationship between science, research, and the clinical practice of medicine, see LEWIS THOMAS, THE YOUNGEST SCIENCE: NOTES OF A MEDICINEWATCHER (1983).

41. Many biomedical researchers have both $\mathrm{PhDs}$ and MDs, but there are also many research physicians with MDs alone. 
conducting research and, as we shall argue below, there ought to be greater incentives in place to create a larger pool of "two-hat" forensic practitioners-individuals who are well trained in a forensic discipline and who have also received substantial formal training in research methodologies. More generally, rank-and-file forensic practitioners without special research-oriented training should be taught through both training and laboratory practice to have respect for research findings. Through appropriate hiring and training, forensic practitioners can understand the value of a research culture and apply research findings in practice. But just as a novice ought not to walk into a forensic science laboratory and begin analyzing casework, neither should forensic practitioners-even those with a bachelor's degree in a scientific discipline and a master's degree in forensic science-be expected, or even necessarily encouraged, to develop or execute a research program on their own. Many practitioners can certainly assist with research - not only by being test subjects, but also by helping to generate research agendas regarding the questions that would help them do their job more effectively, and by partnering with statisticians, psychologists, computer scientists, physical scientists, and research-oriented forensic scientists. But to reiterate: A research culture in forensic science would not turn most practicing forensic scientists into researchers.

What, then, is a research culture? We cannot succeed in providing a robust and complete definition of a research culture, nor shall we attempt to do so. But we can usefully describe core constellations of values that are necessary pieces of a well-functioning research culture in any discipline. We believe these core values are empiricism, transparency, and an ongoing critical perspective; we elaborate on each below.

\section{A. Empiricism}

A research culture should have a deep and fundamental respect for the ideal of empirical support. Claims, both about a field and about particulars, should be expected as a matter of course to be data-driven. Moreover, thoughtful attention should focus on the degree to which the body of available data supports any given claim, and on the relationship between research results, the claim made, and the degree of confidence expressed. Hunches - or claims based on anecdote or personal experience-ought not have the same status as knowledge justified by a substantial body of rigorously produced data. Research that is deeply methodologically flawed should be given no credence. Moreover, research that is methodologically sound should not be touted as offering support for propositions that extend 
beyond the reach of the research design. In short, the extent of sound empirical support for claims should guide practices in the laboratory, conclusions in reports, and testimony in the courtroom.

\section{B. Transparency}

A research culture maximizes transparency, both in the production of knowledge and in internal practices and procedures. Researchers should be encouraged to make data sets available to other researchers, both to share the particular basis for their own claims and to encourage further research. To the extent feasible, laboratories should assist in the production of data sets that can help address key research inquiries, and laboratory personnel should be willing to participate in research projects both as collaborators and as test subjects. To be sure, laboratories may need to delimit access for practical or legal reasons, and laboratory personnel may need to participate as research subjects only to the degree it does not interfere with ongoing operations. But access to data and to examiners as test subjects ought not to depend on being a practicing forensic scientist (as opposed to a researcher from another discipline), nor should it require giving a laboratory veto power or control over publication or dissemination of the results. More generally, information about ordinary laboratory practices, procedures, and protocols should be publically available.

In addition, errors should be recognized as an inevitable part of any human enterprise. Errors should be acknowledged rather than buried under the carpet. Both the individual and the community should take the opportunity to learn from them. We do recognize that forensic laboratories and forensic examiners work within an adversarial legal system. Certainly the us-versus-them mentality that adversarialism generates can discourage disclosure beyond what is legally mandated. The dynamics of crossexamination, in which ordinary human limitations and innocent inconsistencies may be leveraged by opposing counsel into challenges to credibility, can exacerbate this tendency. These forces may combine to create significant pressures opposing transparency. While we do understand this tension-and in the final Part of this Article, we offer some suggestions for managing $\mathrm{it}^{42}$-we reiterate that transparency is a critical value of a functioning research culture.

42. See infra, Part IV. 


\section{Ongoing Critical Perspective}

Claims of knowledge should be taken as provisional and subject to revision in the face of new information. Dogma should be resisted. Research is not one thing, or one study, or once done, never reexamined. Research is an ongoing, incremental process. Research problems should be approached with an open mind. While it is certainly appropriate to have a hypothesis, or preliminary expectation, about what any given research study will show, investigators should follow the data whether or not it supports their original hypothesis, and whether or not it legitimates current practices. Research projects should be designed according to the norms of relevant academic fields. They should not be designed defensively, to produce, or to increase the chances of producing, a particular outcome. ${ }^{43}$ Publication and peer review should occur as a matter of course, and a commitment to publication should not depend on the results. At the same time, we must recognize that the questions that scientific research attempts to answer and the questions that must be answered in a courtroom during a trial are very different. Science is a moving target; answers are always provisional and can be updated as research produces new information or challenges accepted findings. But in a trial, the judge or jury must make pragmatic use of the best available answers to scientific questions at that given moment in time. As a result, the legal system may quite legitimately accept evidence, even scientific evidence, that is good enough rather than perfect. $^{44}$ Waiting for the next study, or postponing a decision, is typically not an option. But these determinations, while decisive in a particular case, should remain epistemically provisional, subject to critical inquiry and revision in a future case if the research warrants it.

43. For an example of a recent research study that was criticized along these lines, see Lisa J. Hall \& Emma Player, Will the Introduction of an Emotional Context Affect Fingerprint Analysis and Decision-Making? 181 FORENSIC SCI. INT'L 36 (2008). For the criticisms, see Itiel E. Dror, On Proper Research and Understanding of the Interplay Between Bias and Decision Outcomes, 191 FORENSIC SCI. INT'L e17 (2009); Michael J. Saks, Concerning L.J. Hall, E. Player, "Will the Introduction of an Emotional Context Affect Fingerprint Analysis and Decision-Making?", 191 FORENSIC SCI. INT'L e19 (2009). For the study authors' response to these criticisms, see Lisa J. Hall \& Emma Player, The Value of Practitioner Research in the Field of Fingerprint Analysis, 191 FORENSIC SCI. INT'L e15 (2009) (responding to Dror's criticism); Lisa J. Hall \& Emma Player, The Value of Practitioner Research in the Field of Fingerprint Analysis, 191 FORENSIC SCI. INT'L e21 (2009) (responding to Saks' criticism).

44. See, e.g., Jennifer L. Mnookin, Of Black Boxes, Instruments, and Experts: Testing the Validity of Forensic Science, 5 EPISTEME 343 (2008); Dale A. Nance, Reliability and the Admissibility of Experts, 34 SETON HALl L. REV. 191 (2003). 


\section{The Present Lack OF A Research Culture in FORENSIC SCIENCE}

A growing number of individuals within the pattern identification disciplines and other forensic fields do fundamentally embrace the values associated with a research culture. Nonetheless, at present, these values are not sufficiently widespread within the pattern identification communities. In this Part, we provide a variety of examples that illustrate the ways in which a research culture is still weak or absent in these disciplines.

In court, forensic analysts asked about the bases for their claims frequently refer to experience and training rather than providing any systematic data. Experience is a legitimate basis for certain kinds of knowledge, but it is deeply problematic for experience alone to be the basis for sweeping claims like individualization. ${ }^{45}$ Moreover, without robust feedback mechanisms to detect and provide information about any possible mistake, experience cannot be a sound warrant for reaching valid conclusions. $^{46}$ If, for example, a document examiner generally has no

45. Individualization is the assertion that an item can be identified to a unique, specific source- - that a print can be identified to a particular finger, to the exclusion of every other finger in the universe; or that a handwriting specimen can be identified as belonging to one and only one particular author out of the entire human population. Because no individual examiner can ever examine every possible specimen in the universe, experience alone cannot justify a claim of individualization, assuming that the potential population of the source is substantial. See, e.g., KAYE, BERNSTEIN \& MNOOKIN, supra note 3, § 7.3.2(c)(2) ("The least useful measures of errors are self-congratulatory statements of the practitioners of a technique. In the absence of systematic, unbiased efforts to root out errors, these estimates amount to little more than reports of the 'I don't remember being proved wrong' variety."). Whether individualization might ever be a plausible claim is a far harder question, and one upon which the authors of this Article do not all agree. See, e.g., Simon A. Cole, Forensics Without Uniqueness, Conclusions Without Individualization: The New Epistemology of Forensic Identification, 8 LAW, PROBABILITY \& RISK 233 (2009); Kaye, supra note 27; Jonathan J. Koehler \& Michael J. Saks, Individualization Claims in Forensic Science: Still Unwarranted, 75 BROOK. L. REV. (forthcoming 2010); Michael J. Saks \& Jonathan J. Koehler, The Individualization Fallacy in Forensic Science Evidence, 61 VAND. L. REV. 199 (2008). But we do agree that experience examining latent prints-even extensive experience looking at tens of thousands of prints-does not provide an adequate warrant for the assertion of individualization.

46. KAYE, BERNSTEIN \& MNOOKIN, supra note 3, § 10.3.3 ("Numerous studies have found that without quick and accurate feedback on correct and incorrect judgments, experience does not produce expertise and experts routinely overestimate their skills.... Casework in forensic handwriting analysis, latent fingerprint identification, toolmark identification, and other patterns and impression evidence comparisons rarely involve ... feedback based on ground truth. The argument that the judgments of these analysts are valid merely because the practitioners have had specialized training or ample experience therefore is unimpressive."); see D. Michael Risinger \& Michael J. Saks, Science and Nonscience in the Courts: Daubert Meets Handwriting Identification Expertise, 82 IOWA L. REV. 21, 33-34 (1996); Mnookin, supra note 44. Even outside forensic science, other disciplines vary with regard to the extent of feedback provided by experience. 
independent knowledge of whether or not her conclusions in any given case are actually correct, how can she learn from her experience? If she never knows when or if she makes an error, how can she adjust her practices to increase accuracy? At present, the efforts to create these kinds of feedback mechanisms are minimal. For example, no laboratory of which we are aware conducts blind proficiency tests that are given in the stream of casework in a pattern or impression discipline, or, for that matter, in any other forensic discipline. Airport security staff, by contrast, are frequently tested covertly in a variety of ways as part of their ordinary workstream. ${ }^{47}$ In one scheme, electronic images of dangerous materials are superimposed onto actual passengers' carryons. Other testing, conducted independently by several agencies, includes no-notice testing of inert bomb parts, weapons, and other prohibited materials. The TSA explains on its website, "Covert testing is a critical element of the aviation security system. It measures effectiveness, identifies vulnerabilities, constantly adapts to challenge officers while incorporating intelligence in a useable way. Simply put, without adopting difficult, covert testing, the aviation security system would not be as effective as it is." 48 Would forensic science not also benefit from covert testing? Another potentially beneficial technique for assessing strengths and vulnerabilities is randomly selected case audits to seek out mistakes or assess the quality of analyses conducted. Some laboratories do carry out such audits, but neither standard practice nor accreditation requirements insist upon it. Institutionalizing procedures like these would serve to check the quality and effectiveness of examiners' experience and would provide critical information about accuracy. ${ }^{49}$

Physicians, for example, get more feedback than forensic examiners via patient outcomes, but this is a noisy signal-patients sometimes recover despite care rather than because of it, and even effective therapies may be ineffective in a given instance either due to bad luck or confounding issues. Mechanics, for example, have better access to feedback than either forensic scientists or doctors: Automobiles are not self-healing and their mechanisms are less complex than bodies.

47. The variety of tests employed are briefly described on the website of the Transportation Security Administration. Covert Testing: Security Screening, TRANSPORTATION SECURITY ADMINISTRATION, http://www.tsa.gov/what_we_do/screening/covert_testing.shtm [hereinafter TSA] (last visited Dec. 26, 2010); see also Dror, supra note 25, at 103.

48. TSA, supra note 47.

49. There are, to be sure, some proficiency tests currently in use. But they are not conducted blindly, nor are they necessarily performed by individual examiners working alone, without collaboration or assistance from colleagues. Nor, for the most part, does their difficulty level mirror actual casework. On the problems with the current proficiency tests in use in the pattern identification field and the potential for using proficiency tests as a method for assessing accuracy, see Lyn Haber \& Ralph Norman Haber, Error Rates for Human Fingerprint Examiners, in AutOMATIC FINGERPRINT RECOGNITION SYSTEMS 339 (Nalini Ratha \& Ruud Bolle eds., 2004); Simon A. Cole, More Than Zero: Accounting for Error in Latent Fingerprint Identification, $95 \mathrm{~J}$. 
Many forensic scientists are too willing to infer scientific validity from the fact of longstanding use. ${ }^{50}$ It is true that some of these forensic techniques have been in use for a substantial period. ${ }^{51}$ It is also true that

CRIM. L. \& CRIminOlogy 985 (2005); Lyn Haber \& Ralph Norman Haber, Scientific Validation of Fingerprint Evidence Under Daubert, 7 LAW, PROBABILITY \& RISK, 87 (2008); Jonathan J. Koehler, Fingerprint Error Rates and Proficiency Tests: What They Are and Why They Matter, 59 HASTINGS L.J. 1077 (2008); Mnookin, Confessions, supra note 35; D. Michael Risinger et al., The Daubert/Kumho Implications of Observer Effects in Forensic Science: Hidden Problems of Expectation and Suggestion, 90 CALIF. L. REV. 1 (2002); Jonathan J. Koehler, Proficiency Tests to Estimate Error Rates in the Forensic Sciences 1-5, (Sept. 19, 2010) (unpublished manuscript) (on file with Northwestern University School of Law).

As for auditing, although the American Society of Crime Laboratory Directors Laboratory Accreditation Board (ASCLD-LAB) does audit some cases as part of its accreditation process, this review takes place only once every five years, and cases reviewed are not selected at random. For a recent instance in which an accredited laboratory had significant problems in its blood analysis not found through the accreditation process, see Locke \& Neff, supra note 5. On ASCLD-Lab Accreditation Requirements, see ASCLD/LAB-INTERNATIONAL, ASCLD/LAB, INC., INTERNATIONAL ACCREDITATION PROGRAM: PROGRAM OVERVIEW (2006).

50. See United States v. Llera Plaza, Nos. CR. 98-362-10, CR. 98-362-11, CR. 98-362-12 (E.D. Pa. Jan. 7, 2002) ('“[T]he ACE-V process and the experts' conclusions have been tested empirically over a period of 100 years ...."' (quoting Gov't Mot. \& Resp. at 112)); United States v. Havvard, 117 F. Supp. 2d 848, 854 (S.D. Ind. 2000) ("[T]he methods of latent print identification can be and have been tested. They have been tested for roughly 100 years. They have been tested in adversarial proceedings with the highest possible stakes-liberty and sometimes life."); Transcript of Trial-Day Three at 114-15, United States v. Mitchell, No 96407 (E.D. Pa. July 9, 1999) ("[E]mpirical studies is when you roll up your sleeves, you do observational analysis. The idea of taking prints, comparing them to other prints to seeing how often things are similar or dissimilar, is empirical studies. The 100 years of fingerprint employment has been empirical studies.") (testimony of Bruce Budowle); David L. Grieve, Simon Says, 51 J. FORENSIC IDENTIFICATION 85, 95 (2001) ("The testability of fingerprint individuality has been conducted for nearly a century, perhaps not in one grand empirical study that captivated the [Daubert] defense, but in the countless smaller studies performed daily in all parts of the globe."); Willam F. Leo, Fingerprint Identification: Objective Science or Subjective Opinion?, 17 PRINT 1, 2 (2001) ("A fingerprint examiner's knowledge and ability can be and is tested, is documented and can be verified, and is evaluated by the courts and juries every time the examiner takes the witness stand."); 60 Minutes: Fingerprints, (CBS television broadcast (Jan. 5, 2003) ("We're winning 41 times out of 41 [admissibility] challenges. I think that says something. We have 100 years of experience; let's make sure that that's clearly out there. And if it wasn't reliable, this certainly would have been discovered many, many years ago."). But see Bruce Budowle et al., A Perspective on Errors, Bias, and Interpretation in the Forensic Sciences and Direction for Continuing Advancement, 54 J. FORENSIC SCI. 798, 799 (2009) ("[F]or many years the forensic science community has pointed to successful admissibility of its science findings, and the opportunity to cross examine expert witnesses, as support of a technique's 'general acceptance' and 'reliability'.... [P]hilosophically we do not advocate successful admissibility as demonstrating good science.").

51. For an example of the early history of fingerprint evidence, see generally COLE, supra note 35; Jennifer L. Mnookin, Fingerprint Evidence in an Age of DNA Profiling, 67 BROOK. L. REV. 13 (2001). For the history of handwriting identification evidence, see generally Jennifer L. Mnookin, Scripting Expertise: The History of Handwriting Identification Evidence and the Judicial Construction of Reliability, 87 VA. L. REV. 1723 (2001) [hereinafter Mnookin, Scripting Expertise]; Risinger et al., supra note 35; D. Michael Risinger, Mark Denbeaux \& Michael J. Saks, Exorcism of 
the number of proven errors for some of these techniques is small relative to the frequency of use (though certainly greater than zero). ${ }^{52}$ And it is true that those pieces of information, combined, provide a degree of support for the claim that latent fingerprint identification, for example, likely has a substantial degree of accuracy (though this evidence obviously does not permit quantification of the precise degree of accuracy). Furthermore, whenever a pattern analyst matches an exemplar to a source, and highly probative, independent evidence of guilt subsequently emerges (or already existed but was unknown to the examiner), this corroborating information provides some indication that the identification technique works, notwithstanding that case information alone can never provide absolute assurance about ground truth. Moreover, if these techniques were being widely used but misidentifying sources at an extremely high rate, one might expect that in some of these cases, powerful contrary evidence supporting innocence would emerge and throw the identification technique's general accuracy into doubt. ${ }^{53}$

While we do therefore grant that this longstanding use establishes something, it establishes less than its advocates suggest. First, the very fact that many kinds of pattern evidence are believed to be especially powerful and persuasive kinds of proof makes inferring validity from its success dangerous. If a fingerprint error leads to a misidentification, might the identified individual nonetheless be convicted, or even plead guilty to avoid a stronger sanction at trial, in the face of evidence that seems virtually indisputable? Convictions, therefore, do not necessarily establish the accuracy of the evidence undergirding them. To argue otherwise is a form of rhetorical bootstrapping. Further support of this point is provided by numerous failures to uncover errors until well after conviction, and sometimes only through highly fortuitous circumstances. ${ }^{54}$ Moreover, the growth of searchable databases with millions of latent fingerprints may create significant new dangers because a large database increases the chances of finding prints from different sources with a high degree of

Ignorance as a Proxy for Rational Knowledge: The Lessons of Handwriting Identification Expertise, 137 U. PA. L. REV. 731 (1989).

52. Cole, supra note 49.

53. We make this last point with caution, because strong evidence can likely only be beaten by equally strong evidence. If, for example, fingerprints are widely seen as dispositive, the emergence of other evidence strongly suggesting innocence may be dismissed as erroneous in the face of the fingerprint evidence.

54. Cole, supra note 49 , at 1020-23. 
coincidental similarity. ${ }^{55}$ In addition, defense challenges to fingerprint evidence, firearms comparison, and other pattern evidence, have been, until recently, very unusual; ${ }^{56}$ as a result, these techniques have operated in court as if they were almost self-proving. ${ }^{57}$

The key point is that longstanding use leads some forensic scientists (and many judges) to treat questions of scientific and systematic validation as moot, or at a minimum, not terribly important. ${ }^{58} \mathrm{~A}$ research culture would care about, and be willing to invest in, rigorous empirical validation even of those matters widely thought to be obvious by practicing forensic scientists.

In addition, a research culture would realize that casework is not research. To be sure, researchers may introduce research questions into the stream of what looks to an analyst like ordinary casework. Covert research of this sort can provide some of the most ecologically valid data about actual practices. Research could also entail examining casework in a structured manner. But an analyst engaged in ordinary casework is not herself conducting research. ${ }^{59}$ Casework may suggest research problems worth exploring. It may lead to hypotheses worth developing. Unusual case findings may be worth discussing at professional meetings or publishing as food for thought. Indeed, the International Association of Identification (IAI) routinely publishes such materials in its journal, and they may provide useful platforms for discussion and expand the experiential basis available to practitioners. But case findings ought not to be mistaken for structured research or empirical data that goes beyond the anecdotal,

55. Itiel E. Dror \& Jennifer L. Mnookin, The Use of Technology in Human Expert Domains: Challenges and Risks Arising From the Use of Automated Fingerprint Identification Systems in Forensic Science 9 LAW, PROBABILITY \& RISK 47, 58 (2010). Databases also play a role in firearms comparison, though the scale of images in the database is significantly smaller than the largest automated fingerprint identification systems.

56. To be sure, in some cases defense counsel may consult with defense experts in fingerprint identification but elect not to present any defense challenge. While we have no data on the frequency of such consultations, our point is that the testimony has typically been presented to the factfinder unchallenged. See generally, COLE, supra note 35; Mnookin, supra note 35.

57. In the early history of handwriting cases, and at present, in civil disputes, document examination has tended to have competing experts on both sides. But this has not generally extended to criminal disputes, especially in modern times. See Mnookin, Scripting Expertise, supra note 51, at 1730; Risinger et al., supra note 35; Risinger \& Saks, supra note 46.

58. See, e.g., Anil K. Jain et al., On the Similarity of Identical Twin Fingerprints, 35 PATTERN RECOGNITION 2653 (2002). For criticism of this approach as unfaithful to Daubert's call for scientific validation, see KAYE, BERNSTEIN \& MNOOKIN, supra note 3, § 7.3.2(a)(4) (arguing that "adversarial testing is not scientific testing"); see also Mnookin, supra note 4, at 36-37.

59. Simon A. Cole, 'Implicit Testing': Can Casework Validate Forensic Techniques?, 46 JURIMETRICS J. 117 (2006). 
whether or not such findings are published. ${ }^{60}$ Unlike planned research, casework does not permit the development of careful controls, defined independent variables, or structured and directed focus. Also, and critically, in casework, ground truth is not known and cannot simply be inferred by a conviction, a confession, or the consensus judgment of experts.

However, we do not mean to set up an unrealistically idealized vision of real research. Legitimate research can vary in its degree of formality and ecological validity. Often, very good research necessarily simplifies some aspects of the real world to focus attention on the matter at issue and to limit potentially confounding variables. Good research can, and usually does, involve both hard questions of design and imperfect compromises. But research does, and must, involve explicit study design. And research reports and publications, comporting with the research culture value of transparency, must be as explicit as is feasible about the nature of the study design. ${ }^{61}$

Forensic analysts have often failed to recognize the limits of what conclusions are actually warranted by a given research result. Research is sometimes used to support conclusions that the data in question simply does not establish. For example, in fingerprint analysis, evidence that supports wide variation in human friction ridge detail is frequently offered to support the examiner's ability to match unknown prints to a source. ${ }^{62}$ While the

60. For examples of the publication of such case studies from fingerprint identification, see, Michael H. Kershaw, Laterally Reversed, 50 J. FORENSIC IDENTIFICATION 138 (2000); Robert D. Reneau, Unusual Latent Print Examinations, 53 J. FORENSIC IDENTIFICATION 531 (2003); Dana Shinozuka, Fingerprints on a Banana Leaf, 50 J. FORENSIC IDENTIFICATION 441 (2000).

61. Transparency does of course have its limits. Among other reasons, confidentiality concerns and maintaining the integrity of the project-which may mean, for example, that examiners do not necessarily know when they are being studied-may require a degree of secrecy. For discussions of the importance of study design, see, for example, KAYE, BERNSTEIN \& MNOOKIN, supra note 3, $\S 12.5$ (discussing "the importance of the design of studies"); HANS Zeisel \& DAVid H. Kaye, Prove IT With Figures: Empirical METHOdS IN LAW AND LITIGATION 11 (1997) (discussing compromises such as "half-a-loaf" experiments to design workable studies); David H. Kaye \& David A. Freedman, Reference Guide on Statistics, in REFERENCE MANUAL ON SCIENTIFIC EVIDENCE 83 (Federal Judicial Ctr. ed., 2d ed. 2000).

62. For a variety of examples of this rhetorical move, see those discussed in Cole, supra note 45, at 235-40. For a recent example of an analysis that makes use of this argument, see, for example, Peter E. Peterson et al., Latent Prints: A Perspective on the State of the Science, 11 FORENSIC SCI. COMM., (2009), available at http://www2.fbi.gov/hq/lab/fsc/backissu/oct2009/review/2009_10_review01.htm. This Article does recognize in passing that latent examiners "do not compare friction ridge skin directly" but rather examine two-dimensional representations that may introduce additional interpretive concerns. Id. But while numerous citations are offered in support of the premises of persistence and individuality of friction ridge skin, the only citation offered to support the claim that latent 
assertion that every fingerprint is different is an inductive claim that cannot definitively be proven empirically (because it is impossible to look at every fingerprint that has ever existed or will exist), the available empirical evidence does support the claims that a high degree of variation in human friction ridge detail exists and that an individual's friction ridges persist to a substantial degree over her lifetime. ${ }^{63}$ Most of us would even be willing to infer, based on what is known, that every human being has prints observably distinguishable from those of every other at some "scale of detection., ${ }^{64}$

But this claim of variability of rolled or digitized fingerprints ${ }^{65}$ does not establish that fingerprint examiners can therefore individualize prints recovered from crime scenes to a particular source or even that the techniques of fingerprint comparison necessarily "work." The right question is not whether all fingerprints actually differ from each other, but rather what conclusions the methods of fingerprint comparison permit, and in what circumstances. Even if every set of ten prints is different from every other, two specific portions of two prints from different individuals might be extraordinarily similar to one another. And even if every area of friction ridge skin is different from every other individual's inked or scanned print, that does not answer whether two such prints from different sources might share enough similarity that an examiner, even if competently using the techniques of the field, might nonetheless mistakenly attribute them to the same unique source.

Moreover, latent print analysis involves difficulties often not present in the analysis of ten prints: Latent images are frequently smaller in surface area than the full print; they are possibly distorted; and they often contain

impressions "translate reliably as a true and accurate representation of what appears on the friction ridge skin" is an untitled FBI laboratory manuscript listed as "in preparation." Id.

63. See, e.g., Christopher Champod \& Pierre A. Margot, Computer Assisted Analysis of Minutiæ Occurrences on Fingerprints, in PROCEEDINGS OF THE INTERNATIONAL SYMPOSIUM ON FINGERPRINT DETECTION AND IDENTIFICATION 305-18 (Joseph Almog \& Eliot Springer eds., 1996); Anil K. Jain et al., On the Similarity of Identical Twin Fingerprints, 35 PATTERN RECOGNITION 2653 (2002); Neumann et al., supra note 32, at 54-64; Cédric Neumann et al., Computation of Likelihood Ratios in Fingerprint Identification for Configurations of Three Minutiae, 51 J. FORENSIC SCI. 1255 (2006); Egli, N., Interpretation of Partial Fingermarks Using an Automated Fingerprint Identification System. PhD, Institut de Police Scientifique et Ecole des Sciences Criminelles, Université de Lausanne, Lausanne, Suisse: 2009; Ne'urim, Israel, June 26-30, 1995: Israel National Police.

64. See KeITH InMAN \& NORAH Rudin, PRINCIPLES AND PRACTICE OF CRIMINAListics: THE PROFESSION OF FORENSIC SCIENCE 128 (2001).

65. A rolled fingerprint is an impression made with ink-usually black ink on white paper-where the individual rolls his inked finger to create a visible impression. Digitized fingerprints involve scanning the friction ridge impression electronically rather than using ink. 
artifacts resulting from the processes necessary to make a latent print visible. $^{66}$ So, the right question is whether, competently using the tools and techniques of latent fingerprint identification, two impressions from two different sources might ever be mistaken as coming from the same source (or, conversely, whether two impressions from the same finger might erroneously be said to come from different sources). Whether the actual ridge patterns on the two fingers in question are or are not "truly" the same is not the critical question. These are significantly different inquiries. The point is to recognize that the claim that friction ridge patterns are highly variable might be a necessary precondition for fingerprint identification, but it does not establish fingerprint analysts' ability to make a match. To suggest otherwise reflects a failure to think carefully and critically about the relationship between an empirical warrant and the claim that is being made.

Numerous examples within the forensic sciences reveal dogma or ideology trumping academic inquiry. For example, in 2001, two forensic science researchers, one of whom was a trained and qualified fingerprint examiner in Switzerland, published a commentary on fingerprint identification. In it, they called for abandoning "absolute conclusions." The authors recognized the inherently probabilistic nature of fingerprint evidence; they allowed that the key question was not the uniqueness of friction ridge skin, but rather the analyst's ability to recognize sufficient information from very limited information; and they advocated replacing experience-and-tradition-based approaches with more transparent and empirically justified practices. ${ }^{68}$ How were these arguments received? At least one commentator responded in print with abject hostility at the notion that interloping statisticians would dare upset the apple cart. ${ }^{69}$ This angry critic wrote:

Once again, identification science is under attack, this time from a shotgun blast by statisticians. They come not to bury fingerprints but to praise it. But as with Shakespeare's Mark Antony, they actually come to incite a riot. Although their main point is relatively simple,

66. To be sure, not all fingerprint comparisons involve latent prints. Sometimes prints found in crime scenes are patent prints-left in ink, blood, or otherwise visible without dusting or processing.

67. Christophe Champod \& Ian W. Evett, A Probabilistic Approach to Fingerprint Evidence, 51 J. FORENSIC IDENTIFICATION 101 (2001).

68. Id.

69. See Steve McKasson, I Think Therefore I Probably Am, 51 J. FORENSIC IDENTIFICATION 217 (2001). 
it is mired deeply in rhetoric. One might describe it as opaque rather than transparent. ${ }^{70}$

The author later asserts:

This commentary is indeed a vicious attack and any identification expert who does not see it as such has not read it closely enough. Surely the authors cannot expect that this will cause the scales to fall from the eyes of examiners everywhere and that the errors of the last hundred years will be revealed at last.... What then can be their motive for putting this forward at this time? ${ }^{71}$

He finally adds:

As with most propaganda, it is masked, although not particularly well in this instance.... Although this article may be intended to demonstrate that identification specialists do not know enough about statistics, what it has clearly demonstrated is that statisticians do not know enough about identification. ${ }^{72}$

It is not clear which is more worthy of note: the vitriol and sarcasm of the response, or the fact that the journal published it notwithstanding this extraordinary tone.

More recently, in the face of evidence presented in another article that contextual information may bias the decisions of fingerprint analysts, ${ }^{73}$ one commentator responded with the following statements in a letter to the editor:

[A]ny fingerprint examiner who comes to a decision on identification and is swayed either way in that decisionmaking process under the influence of stories and gory images is either totally incapable of performing the noble tasks expected of him/her or is so immature that he/she should seek employment at Disneyland.... And I do find it rather unsavoury that those within our own ranks, who ought to know better and are aware just how reliable the fingerprint system is, continue to provide fuel for those within the media and Press who seem to relish attacking what is the most valuable tool in the investigating officer's armoury. ${ }^{74}$

Rather than discuss the merits of the research, the letter writer attacks those test subjects who showed themselves to be susceptible to biasing

70. Id. at 217 (citation omitted).

71. Id. at 221.

72. Id.

73. The study under discussion was Dror \& Charlton, supra note 32. 231.

74. Martin Leadbetter, Letter to the Editor, FingERPRINT WHORLD, Sept. 2007, at 231, 
information as incompetent or immature. Given that psychological research shows that all humans are potentially susceptible to the effects of biasing information, this letter writer essentially proposed that fingerprint examiners might best make a mass exodus to Disneyland.

To be sure, these examples of blustery responses to unwelcome points of view obviously do not represent the views and attitudes of all forensic practitioners. But neither response provoked any apparent public outrage from the forensic science community. Not a single follow-up letter was published, criticizing these authors for their sputtering and dogmatic responses to thoughtful research and analysis.

Admittedly, human endeavors are quite frequently dotted with examples of resistance to new theories that challenge the status quo. ${ }^{75}$ Regardless, a sign of a mature discipline with a well-entrenched research culture is a willingness to engage respectfully with opposing viewpoints; it is a commitment to focusing on the merits of proposed theories, the adequacies of research methodologies, and the assessments of the data rather than resorting to inflated rhetoric or personal attacks. Forensic scientists have sometimes found it too easy to respond with a personal attack instead of - or layered on top of - substantive assessment of critics' arguments. Even one of the authors of this Article regrets portions of one of his early publications that now seem to him to have taken too derisive a tone toward some of the critics of forensic science (including, indeed, other authors of this Article). ${ }^{76}$ In a research culture, participants should, ideally, learn from disagreements rather than fear them. We believe it is a significant step forward that those who have found themselves (literally) on opposite sides of the courtroom are now, by coauthoring this Article, not only willing to engage with one another, but are finding many shared views. But the development of a research culture in these areas still has a long way to go.

When accused of being insufficiently research-based, or insufficiently linked to academia, practitioners in the pattern identification fields have

75. Consider, for example, Thomas Kuhn's famous book, The Structure of Scientific Revolutions, and his arguments and examples detailing how "normal science" frequently proceeds even in the face of anomalous findings, and how most researchers in any given paradigm remain bound to it notwithstanding contradictory evidence. THOMAS S. KUHN, THE STRUCTURE OF SCIENTIFIC REVOLUTIONS (1962). For further examples, see Bernard Barber, Resistance by Scientists to Scientific Discovery, 134 SCIENCE 596 (1961). Given these attitudes in areas with robust commitments to a research culture, it is not surprising to find similar dynamics in an area where the research culture commitment remains weak.

76. Glenn Langenburg, Defense Against the Dark Arts, 43 CHESAPEAKE EXAMINER 1, 5-6, $12(2003)$. 
sometimes responded by invoking the scientific foundations articulated by the pioneers of their fields. Whatever the qualifications of these early practitioners, in a healthy research culture, the scientific bona fides of a profession would be unlikely to depend on these pioneers of the distant past. For example, one published response to an article criticizing the lack of adequate scientific foundation in the forensic sciences emphasized the academic credentials of forensic pioneers like Calvin Goddard, J. Howard Mathews, and Sir Francis Galton. ${ }^{77}$ Goddard (1891-1955) trained as a physician, spent his career partly in the military, and substantially contributed to the establishment of forensic firearms comparison as a field. J. Howard Mathews (1881-1970) published a major firearms treatise in $1962,^{78}$ ten years after retiring from an academic position in chemistry. Sir Francis Galton (1822-1911) was a significant scientific intellectual of the Victorian era, with interests as diverse as meteorology, eugenics, heredity, statistical analysis, and fingerprints. ${ }^{79}$ Without belittling the significant intellectual contributions of these pioneers, a robust research culture should be continuous and current. Century-old work or the credentials of pioneers, however impressive, has little direct relevance to questions of present-day scientific legitimacy. ${ }^{80}$

Another major limitation of the current forensic science culture relates to several of the publication venues for the pattern identification field. Several of the most significant journals focused on publishing pattern identification research simply do not comport with broader norms of access, dissemination, or peer review typically associated with scientific publishing. For example, the AFTE Journal, a quarterly publication of the Association of Firearm and Toolmark Examiners, has published numerous articles on firearms identification. ${ }^{81}$ Worldcat-the largest online catalog of library

77. CRIME LAB Report, ForEnsic PATtern IDENTIFICATION: A History LeSSON, AND SOME ADVICE, FOR SAKS AND FAIGMAN 4 (2009), available at http://www.crimelabreport.com/library/pdf/1-09.pdf.

78. $1 \mathrm{~J}$. HOWARD MATHEWS, FIREARMS IDENTIFICATION (2d ed. 1973).

79. See generally Michael Bulmer \& Francis Galton, PiONEER OF HeREdity AND BIOMETRY (2003).

80. For similar observations concerning the handwriting identification, see Risinger et al., supra note 35, at 738-40. The handful of formal studies on the "black box" reliability of signature authentication has not changed the almost exclusive practical reliance on century-old sources. Id. at 773 .

81. Many of the articles claimed by firearms analysts to validate their practices have been published in AFTE. See, e.g., Ronald G. Nichols, Defending the Scientific Foundation of the Firearms and Tool Mark Identification Discipline: Responding to Recent Challenges, 52 J. FORENSIC SCI. 586 (2007). We take no position here on whether these publications and research bases provide an adequate foundation for the claims of firearms identification. Our point is that this journal is deemed by members of the community to be a critical publication venue. For a view critical of 
materials, which includes the holdings of 72,000 libraries worldwide, including virtually every university-based library in the United States-lists only eighteen libraries with a copy of this journal in their holdings. ${ }^{82}$ Furthermore, the AFTE Journal does not appear to be indexed or included in any major indexing service anywhere. ${ }^{83}$ The only available index to AFTE was created by an individual firearms examiner on his own initiative and was not continued past $2005 .^{84}$ Moreover, peer review of submissions to AFTE is not blind; the author and the reviewer are both aware of each other's identity. ${ }^{85}$ In addition, the peer reviewers appear to come entirely from the editorial board, which consists entirely of AFTE members, and , therefore includes no members from outside the toolmark and firearms practitioner community). ${ }^{86}$ This journal therefore appears to have extremely limited dissemination beyond the members of AFTE itself; completely lacks integration with any of the voluminous networks for the production and exchange of scientific research information; and engages in peer review that is neither blind nor draws upon an extensive network of

the research basis of firearms comparison claims, see Adina Schwartz, A Systemic Challenge to the Reliability and Admissibility of Firearms and Toolmark Identification, 6 COLUM. SCI. \& TECH. L. REV. 1 (2005).

82. WorldCat lists a total of nineteen libraries in three separate file listings. However, the Library of Congress is listed twice. The American libraries that subscribe to AFTE are, in full: Cal State, Sacramento; George Washington University; Stetson University College of Law; Ogeechee Technical College; Grambling State University; Truman State University; John Jay College of Criminal Justice; Case Western Law School; Mercyhurst College Hammermill Library; George Mason University; Virginia Commonwealth University; and the Library of Congress. To be sure, Worldcat's listings may to a certain degree understate access. First, despite its extensive inclusions, we recognize that some libraries are not in Worldcat. Second, we recognize that at some institutions, if an individual faculty member has a subscription, the library may elect not to pay for institutional access. However, this issue should have a potential effect on all journals associated with membership organizations, not simply forensic science journals; and by any standard, the number of research libraries subscribing to AFTE is remarkably small. Moreover, a faculty member with access significantly limits broader dissemination to those outside the individual faculty member's ambit.

83. This information comes from Ulrichsweb, an authoritative source of information on periodicals. See generally ULRICHSWEB-THE GLOBAL SOURCE FOR PERIODICALS, http://www.ulrichsweb.com/ulrichsweb/ (last visited Dec. 30, 2010).

84. This index can be downloaded at AFTE Journal Keyword Index ASS'N OF FIREARM \& TOOL MARK EXAMINERS (Oct. 24, 2005), http://www.afte.org/ExamResources/journalindex.htm. It appears to be the individual work of an Albuquerque Police Department firearms examiner.

85. See the description at AFTE Peer Review Process, ASS'N OF FIREARM \& TOOL MARK EXAMINERS (Aug. 2009), http://www.afte.org/Journal/PeerReviewProcess.htm; see also Dominic J. Denio, The History of the AFTE Journal, the Peer Review Process, and Daubert Issues, AFTE J., Spring 2002, at 210, 210-14.

86. Indeed, AFTE membership is, for the most part, open only to practicing firearms and toolmark examiners (or those in training for the profession). For membership categories, see http://www.afte.org/Membership/membership.htm. For a list of the editorial review panel, see http://www.afte.org/Journal/EditorsCommittee.htm. 
researchers. None of this is compatible with an accessible, rigorous, transparent culture of research. ${ }^{87}$

The Journal for Forensic Identification (JFI), the journal of the International Association of Identification, suffers from similar limitations, though to a slightly lesser degree. Worldcat reports seventy-two libraries that contain print holdings of the journal and 123 that subscribe to the electronic version through ProQuest. ${ }^{88}$ (The JFI is included in a few major indexes, including ProQuest and SCOPUS. This quantum of accessibility may be adequate to permit an intrepid researcher to locate materials published within JFI. But it still fails to meet conventional standards of research access. ${ }^{89}$ Indeed, the JFI is not even listed in the Web of Science, a large collection of more than 10,000 journals over a wide range of areas. Like the AFTE Journal, it is not analyzed in the databases assessing journal

87. For a discussion of the nature of scientific peer review, see KAYE, BERNSTEIN \& MNOOKIN, supra note 3, § 7.3.2(b).

88. JFI does come in an electronic version, but it is available to libraries only with purchase of a large and expensive criminal justice periodicals package, rather than by itself. This also suggests that some of the electronic holders were not specifically choosing the JFI but received it along with whatever sources led them to the aggregate database. Whatever their motivation, access is access, and the subscribers to the larger database are providing access to those with access to that library. Some institutions subscribe to both the electronic and the print versions, so the total number of libraries providing access to the journal is slightly fewer than adding the two numbers would suggest. However, it appears that Worldcat likely understates electronic access, as not every library that lists with Worldcat lists every electronic holding they receive as part of a package. A call to ProQuest confirmed that JFI is not available for subscription alone but is a part of the Criminal Justice Periodicals Index. The ProQuest representative indicated that there are more than two hundred subscribers to this database but was unable to provide any more exact figures. Assuming that this number is accurate, it suggests either that some subscribers are not members of Worldcat, some subscribers are not listing their electronic access on Worldat, or, as is most likely, a combination of both. Therefore Worldcat's numbers for electronic access need to be taken with a grain of salt. However, this electronic access subscription number for JFI can still be loosely compared with that of other journals. There is no reason to believe that libraries would be less likely to report this specific holding as opposed to other electronic holdings, so relative comparisons are likely meaningful, even if the specific number cannot be trusted.

89. It would be unfair to compare JFI to the major publishing venues of a broad scientific or social scientific discipline, as pattern identification is a subfield of forensic science. A more reasonable comparison might be, for example, Social Studies of Science, the journal published by an academic association (the Society for the Social Study of Science) with many fewer members than the IAI, and associated with an extremely small academic subfield (sociology of science). This journal is listed on Worldcat as having 543 subscribers to the print version and 712 to the internet version. Like the JFI numbers, this electronic number likely understates access, probably even more substantially than JFI. Social Studies of Science is available as a package through its publisher, Sage. It is not clear that libraries providing access through Sage, or through the widely available JSTOR, would list such access on Worldcat, or that those libraries that provide both print and electronic access would include two separate listings in the catalog. 
impact. ${ }^{90}$ The JFI also gives its authors "plaques" to mark the fact of publication. While this could be viewed as a nice gesture to recognize an author's efforts and to spur submissions, it is certainly not a practice widely seen in other disciplines, and it implicitly treats publication as an unusual accomplishment, rather than an expected consequence of engaging in research. Fingerprint Whorld, a quarterly United Kingdom-based journal that provides another important source of information to fingerprint examiners, is similarly difficult to acquire through libraries.

Several other publications include pattern-identification-related articles, most notably the American Academy of Forensic Sciences's Journal of Forensic Sciences (JFS); ${ }^{91}$ and Forensic Science International (FSI) (published in Europe). These journals have a significantly greater degree of library dissemination and meet more of the typical indicia expected for research journals. They are widely indexed (including in Scopus, Pubmed, Medline, Web of Science, and numerous other locations), and they are included among the 7300 scientific journals that are assessed for impact by the ISI/Web of Knowledge. However, it is perhaps worth noting that none of the top fifty most cited articles in either JFS or FSI relates to pattern identification. $^{92} \quad$ This does not discredit those articles in pattern identification that do appear in JFS and FSI. It illustrates, however, both that pattern identification disciplines make up only a small portion of the journals' overall focus, and that none of the journals' most well-known and widely cited articles come from these fields. ${ }^{93}$ While the JFS is both peer reviewed and adequately disseminated to a broad research and practitioner

90. Impact ratings are an effort to evaluate how much scholarly 'impact' specific journals or individual articles may have. Impact ratings, which focus on how often journal articles are cited, are imperfect proxies for journal influence and quality. Nonetheless, it is fair to conclude that an unrated journal has a low impact.

91. Worldcat has 919 listings for the print version and 301 for the electronic version of JFS. The same caveats about these numbers apply. Note also that the journal is listed multiple times, and these numbers derive from adding the various listings without cross-checking for possible duplicate listings. Note also that many print subscribers likely also have electronic access.

92. This was established by searching the ISI/Web of Knowledge by journal title and sorting by times cited. For a broader (but slightly dated) analysis of what topics in forensic science are highly cited, see Alan W. Jones, Which Articles and Which Topics in the Forensic Sciences are Highly Cited, 45 SCI. \& JUST. 175 (2005). In Jones's analysis, the topics garnering the most citations came from toxicology, criminalistics (almost entirely DNA-related), and pathology. Id. at 178-80. Whether these disparities are solely the result of population differences across different forensic specialties, or also reflect meaningful differences in the quantum of research engagement, cannot be determined without further study.

93. To be fair, pattern identification fields make up a relatively small portion of the total membership of the AAFS. However, this underscores the value of having a serious, welldisseminated journal focusing on these areas in particular. 
community, from the perspective of generating a robust research culture in the forensic sciences, one aspect of the AAFS policy is troubling. Presenting new research at the AAFS' annual meeting obligates the presenter to give the JFS a right of first refusal (albeit unenforceable) on the relevant material. ${ }^{94}$ While the JFS is a reputable journal, a researcher's publication options should not be restricted because of presentation to the forensic science community. Forensic science would benefit from broader dissemination and more frequent publication in high-impact journals that are not exclusively geared to the forensic sciences. ${ }^{95}$

While we firmly believe that an adequate research culture does not yet exist in the pattern and impression evidence disciplines, and is distressingly weak throughout many areas of forensic science, we are more interested in thinking constructively about how to remedy this situation than in pointing fingers and assessing blame. However, to prevent misunderstanding, it is worth making several points explicit. First, in our view, this lack of a research culture is not forensic scientists' fault. The two most significant causes are a dearth of funding and the fact that prosecutors, investigators, and the courts are the primary clients of forensic science. Until recently, very little federal grant money was available for non-DNA forensic science research. $^{96}$ This lack of funding, combined with the general paucity of resources in triage-driven, overworked laboratories, made research an exceedingly unlikely central priority. In addition, few practitioners had the background skills to develop substantial research programs even if the institutional climate had supported it.

Equally significant, even after Daubert v. Merrell Dow Pharmaceuticals, Inc. ${ }^{97}$ emphasized the need for judicial gatekeeping to assure the validity of

94. See Info for Authors, AM. ACAD. OF FORENSIC SCIS., http://www.aafs.org/info-authors-0 (last visited Dec. 30, 2010) ("JFS reserves the right of first consideration for publication of any work accepted for presentation at an annual meeting of the AAFS, and authors must not submit their work elsewhere for a period of six months following the annual meeting at which the work was presented. If a manuscript has not been accepted for publication, or is not under active consideration by JFS, at the end of the six-month period, the interest of JFS in the manuscript automatically terminates.").

95. Given this rule, it is not surprising that one recent study found that a majority of those papers presented at the AAFS that were later published in a peer-reviewed journal were published in the JFS. Silvia Tambuscio et al., From Abstract to Publication: The Fate of Research Presented at an Annual Forensic Meeting, 55 J. ForENSIC SCI. 1494, 1496 (2010). The same study also found that, in the annual meeting studied, only 16.4 percent of research presentations led to publication, a lower number than the vast majority of presentation-to-publication ratios that have been studied. Id. This unusually low publication ratio is yet another indicator of the lack of a robust research culture.

96. Max M. Houck, A Vicious Cycle, 1 ForEnsiC SCI. POL'Y \& MGMT. 123, 124 (2009).

97. 509 U.S. 579 (1993). 
expert evidence in court, most judges confronted with pattern identification evidence have continued to admit it without restriction. ${ }^{98}$ If courts are not going to insist upon better evidence of validity, if they are instead going to continue to permit forensic scientists to reach extremely strong conclusions about their own abilities to make identifications, and if legal challenges remain both relatively rare and generally unsuccessful, then why should the forensic science community consider changing its practices? If an examiner is permitted, indeed expected, to express extremely high confidence about an individualization, what incentives exist to pursue research that would, at best, justify this confidence, and at worst, reveal hitherto unrecognized limitations? The judicial response to these identification techniques has therefore been a powerful force both enabling and preserving this status quo. If a few more brave judges had required additional evidence to support the claims being made and mandated a closer fit between claims made and the research supporting them, the forensic science community would have had an extremely strong incentive to develop and provide precisely this information. ${ }^{99}$

Moreover, most practicing forensic scientists in pattern and impression evidence, and in most other forensic disciplines as well, are not actually qualified to pursue the necessary research. Until recently, many laboratories did not necessarily require a college degree or any formal

98. For discussion of these admissibility challenges, see FAIGMAN ET AL., supra note 3. Some recent cases evincing more skepticism, though generally still admitting the evidence, are discussed in KAYE, BERNSTEIN \& MNOOKIN, supra note 3, and Mnookin, supra note 4, at 121213, 1241-65. For an interesting procedural order from one district court judge, see Procedural Order: Trace Evidence, No. 1:08-cr-10104-NG (D. Mass. Mar. 8, 2010), available at http://www.swgfast.org/Resources/100310-GertnerProceduralOrder.pdf (making clear that in the wake of the NAS Report, admissibility of such forensic science evidence "ought not to be presumed; that it has to be carefully examined in each case, and tested in the light of the NAS concerns, the concerns of Daubert/Kumho case law, and Rule 702 of the Federal Rules of Evidence," and describing pretrial procedures to govern any such challenges).

99. See Mnookin, supra note 4; Risinger \& Saks, supra note 46, at 65-66; D. Michael Risinger, Goodbye To All That or a Fool's Errand, by One of the Fools: How I Stopped Worrying About Court Responses to Handwriting Identification (and "Forensic Science" in General) and Learned to Love Misinterpretations of Kumho Tire v. Carmichael, 43 TULSA L. REV. 447, 471-75 (2007). Some judges have evinced genuine concern about whether some pattern identification passes Daubert, and some have restricted the evidence (for example, by permitting descriptions of similarities but no conclusion regarding identity, or by prohibiting claims of absolute certainty about identity to the exclusion of all others) or occasionally excluded it. For examples of these approaches, see United States. v. Taylor, 663 F. Supp. 2d 1157 (D.N.M. 2009); United States v. Green, 405 F. Supp. 2d 104 (D. Mass. 2005); United States v. Llera Plaza, 179 F. Supp. 2d 492 (E.D. Pa. 2002), vacated, 188 F. Supp. 2 d 549 (E.D. Pa. 2002); United States v. Hines, 55 F. Supp. 2d 62 (D. Mass. 1999); Maryland v. Rose, No. K06-0545 (Md. 2007). However, most admissibility challenges have resulted in the admission of the pattern evidence without restriction. 
science training. ${ }^{100}$ Even those with a BS in forensic science or some other scientific discipline have not typically received significant training in the development of research design. Experience may provide the basis for determining what questions to ask, but most pattern identification analysts, even with entirely noble intentions, would not be qualified to design or develop sophisticated research projects to answer those questions. We neither fault these practitioners for failing to do so, nor do we expect them to become primarily focused on research themselves. We do, however, expect them to become more sophisticated in thinking about data and the legitimacy of inference. Expecting most practicing pattern analysts to become PhD-level researchers is not realistic, nor is it even a good idea. If, however, practitioners at all levels operated within a research culture, they would hone their critical thinking skills and regularly question what basis supports their claim to knowledge, both in an individual case, and more broadly in a given discipline. Moreover, while all laboratory personnel need not, and indeed should not, be researchers themselves, it would not be unrealistic to require certain key personnel-perhaps the lead technical worker in a unit, and whoever is authorized to approve standard operating procedures - to have some minimum research qualification and experience.

\section{Creating a Research Culture: Some Possible Steps TOWARD CHANGE}

Culture is sticky. We fully recognize that cultural change does not come easily, and we do not mean to assume naively that the culture of pattern identification can be modified with ease. We do believe that the current controversies, the NAS Report, and its aftermath create the opportunity for both greater self-reflection and cultural change. We already see a number of positive developments and glimmers of future changes on the horizon. ${ }^{101}$

100. Peterson et al., supra note 62 (noting that while in the past, "examiners were required to have, at a minimum, a high school diploma," many labs are increasing educational requirements). SWGFAST recommends that new entrants to the field have a minimum of a college degree from an accredited institution that included scientific coursework. See SCIENTIFIC WORKING GROUP ON FRICTION RIDGE ANALYSIS, STUDY \& TECHNOLOGY, STANDARDS FOR MiNIMUM QUALIFICATIONS AND TRAINING TO COMPETENCY FOR FRICTION RIDGE EXAMINER TRAINEES (2010), available at http://www.swgfast.org/documents/qualificationscompetency/100310_Qualifications_Training_Competency_FR_1.0.pdf.

101. For a few examples of interesting developments, see IAI Resolution 2010-18, supra note 23 (reflecting a "change [in] the official position of the Association related to Friction Ridge Examinations based on advances in the science and scientific research" by no longer prohibiting fingerprint examiners from testifying in probabilistic language); the NIST/NIJ working group on 
In this final Part of the Article, we wish to describe briefly a variety of steps that could help to create and institutionalize a research culture within the pattern identification sciences. Is every one of these necessary? Taken together, would they be sufficient? We are not certain of the answer to either of these questions, but we do believe that these suggestions would offer meaningful and constructive steps toward positive change.

Our suggestions also reflect an effort to be realistic about what is possible. For this reason, we are not calling for the courts to transform their approach to the admissibility of forensic science. Many (though not all) of us believe that this would be intellectually appropriate and, while potentially disruptive in the short run, could also have beneficial cultural effects in the medium term. If, for example, courts insisted on better errorrate information as a precondition for admissibility, the incentives for its production would dramatically increase. Given that the legal system is the major client for forensic science, the requirements courts impose will naturally, and perhaps inevitably, influence what quantum and what kinds of research are deemed necessary by the community itself. Indeed, to a significant degree, the current state of affairs is the direct product of the courts' nearly nonexistent gatekeeping for these forms of evidence. Had the courts applied Daubert v. Merrell Dow Pharmaceuticals, Inc. ${ }^{102}$ with an intensity in the forensic sciences similar to that seen in, say, the toxic torts arena, there is little doubt that the forensic science community would have become forceful advocates for whatever research seemed necessary to justify admissibility. ${ }^{103}$ Instead, while some judges have engaged in a certain degree of hand wringing, few have actually insisted upon empirical data to support forensic examiners' claims. Unfortunately, given their responses to forensic science challenges over the past few years, the Daubert test's

Human Factors in Friction Ridge Identification, which has brought together a broad range of perspectives and signals a welcome willingness of leaders of the fingerprint community to engage with academics ranging from statisticians to law professors; an NSF-funded workshop at Northwestern bringing together cognitive psychologists not previously involved in forensic inquiries with forensic science practitioners; a procedural order by a district court judge signaling a clear willingness to take the issues raised by the NAS Report seriously (detailed in supra note 98); NAT'L SCI. \& TECH. COUNCIL, COMM. ON SCI., SubCOMM. ON FORENSIC SCI., http://www.forensicscience.gov (last visited Dec. 30, 2010) (describing the creation by the White House's Office of Science and Technology Policy of a Subcommittee on Forensic Science, "to assess the practical challenges of implementing recommendations in the 2009 National Research Council (NRC) report," and to advise the White House regarding how to achieve the Report's goals).

102. 509 U.S. 579 (1993).

103. But see Joseph Sanders, Applying Daubert Inconsistently?: Proof of Individual Causation in Toxic Tort and Forensic Cases, 75 BROOK. L. REV. 1367 (2010). 
fuzziness and flexibility, and the limited appellate review that an 'abuse-ofdiscretion' standard provides, there is little reason to believe that the judiciary will become a force that spurs cultural transformation in the forensic sciences.

Most of us support the idea of creating an independent entity (such as the National Institute of Forensic Science (NIFS) recommended by the NAS) that supports and governs the forensic science community, including its research activities. We believe that the major reforms that we and others have called for would best be accomplished via a corresponding structural change and through the leadership and oversight that a new agency, if carefully conceived and implemented, could provide. But while the Senate Judiciary Committee is considering a legislative proposal that may create an independent entity within the National Institute of Justice to pursue some of what NIFS might have accomplished, ${ }^{104}$ the politics of creating a new federal agency seem unmanageable at the moment.

Given our pessimism regarding the likelihood that the courts will be major agents of change, or that a new agency will transform these fields, what, then, can and should be done to improve the research culture within these fields?

\section{A. Increased Funding}

One of the biggest obstacles to forensic science research has been the absence of specific federal funding to support it. The National Science Foundation (NSF) has at times funded forensic science research projects, ${ }^{105}$ but the NSF focuses on fundamental, rather than applied research. Some of the necessary research within these fields may make important methodological and theoretical contributions to broader disciplines, such as

104. See Int'l Ass'n for Identification, Preliminary Outline of Draft Forensic Reform Legislation (May 5, 2010), available at http://www.theiai.org/current_affairs/20100505_Draft_Outline_of_Forensic_Reform_Legislation.p df; see also Letter From Joseph P. Bono, President, Am. Acad. of Forensic Scis., to The Honorable Patrick J. Leahy, Chairman, Senate Comm. on the Judiciary (June 14, 2010), available at http://www.aafs.org/sites/default/files/pdf/AAFSResponseToDraftOutline14June2010.pdf.

105. A search of the NSF database reveals at least six funded projects that are squarely connected to forensic science: Cognitive Bias and Forensic Science, Jonathan J. Koehler; Understanding Jurors Use of Highly Diagnostic Statistical Evidence, Jonathan Koehler; Statistical Methods for Fingerprint Image Analysis, Sarat Dass; Why Do Forensic Evaluators With Access to the Same Information Come to Different Conclusions When Retained by Opposing Sides in Legal Proceedings?, Marcus Boccaccini \& Daniel Murie; Jurors' Evaluations of Forensic Science, William C. Thompson; and, Dissertation Research: Taming the Hypervariable Witness: The Introduction, Contestation, and Regulation of Forensic DNA Evidence in the American Legal System, John Beatty. 
probability theory, statistics, decision research, and cognitive psychology. These kinds of projects might be appropriate for NSF funding. But much of the research critical for the forensic sciences may not make a novel methodological or theoretical contribution to other academic fields. NSF does not traditionally fund these more applied forms of inquiry. Forensic science research (apart from DNA profiling) has not received significant funding through other sources either. ${ }^{106}$ For example, until very recently, the National Institute of Justice (NIJ) funded very little foundational research in the pattern identification sciences. ${ }^{107}$ This has begun to change in the last year, partly as a function of the NAS Report itself. In 2009, NIJ posted a solicitation for funding up to $\$ 10$ million to applications proposing "Fundamental Research to Improve Understanding of the Accuracy, Reliability, and Measurement Validity of Forensic Science Disciplines." 108 Similar solicitations appeared in 2010. ${ }^{109}$ In addition, the National Institute of Standards for Technology (NIST), the Department of Defense, the Department of Homeland Security, and the FBI have begun to provide some additional, albeit still limited, funding for pattern identification research. ${ }^{110}$

These numbers, while far better than nothing, are a drop in the bucket. ${ }^{111}$ More funding-and some stable and consistent forms of funding - is critical for a research culture to take root and flourish. These funding sources sorely need to be independent from law enforcement. Solicitations should be as broad in scope and as widely disseminated as possible to encourage greater involvement from discipline-based academic researchers from fields like physical science, psychology, statistics, and computer science. Funding could help attract creative, cutting-edge work from diverse researchers applying the methods and techniques of their fields. While forensic science has not typically been a domain of major inquiry for these disciplines, substantial funding will likely pique the interest of some academic researchers from a variety of disciplines. ${ }^{112}$

106. See, e.g., Houck, supra note 96 , at 124 (showing paltry federal research funding for forensic science compared with other fields of science and engineering).

107. An earlier NIJ solicitation was withdrawn in the wake of an early Daubert challenge to fingerprint evidence. See United States v. Mitchell, 365 F. 3d 215, 232 (3d Cir. 2004).

108. http://www.ncjrs.gov/pdffiles1/nij/s1000878.pdf.

109. Several of the coauthors of this Article have applied for and/or received NIJ funding under these solicitations and others.

110. For example, see the listings at http://www.tswg.gov/subgroups/isf/isf.html.

111. Houck, supra note 96, at 123-24.

112. We note that selection of funding recipients must also operate in accordance with the values of a research culture. Nonresearching practitioners should not substantively evaluate the research design merits of proposals, except in relation to practical concerns about which their 


\section{B. Improving Forensic Education to Enhance a Research Culture}

In addition to encouraging greater participation from university-based researchers from a variety of fields, we strongly believe that forensic science would benefit from the emergence of a cohort of individuals with the skills and the background to operate both in the academic research community and in the world of practitioners. Currently, in the pattern identification field, the number of practicing analysts with a $\mathrm{PhD}$ in any discipline is quite small indeed. (This is in stark contrast to a number of other forensic fields, including DNA analysis and toxicology, in which a significant number of analysts hold $\mathrm{PhDs}) .{ }^{113}$

The majority of forensic practitioners in pattern identification need not—and should not-pursue PhDs. But if some relatively small fraction of practitioners were full citizens of both the world of research and the world of practice, it would offer enormously beneficial spillover effects. These practitioner-researcher hybrids could wear two hats by being true insiders in both communities. They would be valuable translators, mediators, and educators in both domains. They could both convey to fellow practitioners the need for a research-based approach and contribute to ensuring that research focuses on areas of genuine and important concern to practitioners. ${ }^{114}$

experience produces expertise. Practitioners' views on what research questions are important, and why, can absolutely be considered, and if research proposals make unwarranted or naïve assumptions about how laboratories operate, that too is relevant to evaluation. But the academic merits of any given research design should be assessed by those with the research qualifications to evaluate them. A recent report revealed a failure of precisely these values at the National Institute of Justice, which suggests that it might be a problematic choice to spearhead the forensic reform effort. OfFICE OF THE INSPECTOR GEN., U.S. DEP'T OF JUSTICE, U.S. DEPARTMENT OF JUSTICE AUdiT of THE NATIONAL INSTITUTE OF JUSTICE'S PRACTICES FOR AWARDING GRANTS AND CONTRACTS IN FISCAL YEARS 2005 THROUGH 2007, at xxiii-xxiv (2009). While we strongly advocate greater funding for fundamental forensic science research, we recognize that funding will only produce useful research and strengthen the research culture if it is administered and distributed in ways concordant with the values of a research culture. It is worth noting that both institutional capacity concerns and the need for independence from law enforcement pressures were reasons that the NAS Report strongly urged the creation of NIFS as an entirely new and independent agency. See NAS REPORT, supra note 8, at 20-21.

113. Admittedly (and perhaps ironically), our evidence for both of these claims is anecdotal and based on experience rather than the product of careful empirical study.

114. Of course, it is theoretically possible that they would be captured by one perspective or the other and either lose all touch with practical concerns or become highly credentialed spokespeople for the status quo. We think, however, that precisely because culture is sticky, significant exposure and integration into both domains will more likely produce individuals who, like those truly bilingual in two languages, can mediate, engage, and translate in both worlds. 
Given the significant value that would result from encouraging a small number of two-hat researcher-practitioners, the government ought to consider funding generous competitive grants for highly qualified pattern identification practitioners to pursue advanced graduate training in relevant disciplines such as physical science, statistics, cognitive psychology, computer science, or at a research-focused forensic science program. These grants could, for example, pay half of an analyst's salary for a period of several years to allow the time and financial resources to pursue a $\mathrm{PhD}$. A few highly competitive and well-funded grant opportunities of this kind would significantly contribute to the research culture of forensic science.

Another important step for creating and nurturing a research culture is the creation of research-based forensic science programs within academic institutions. While two-hat experts with a $\mathrm{PhD}$ in a substantive nonforensic field along with practical forensic experience can be key mediators between a research culture and forensic practice, research programs also have a place within forensic science departments. Academic forensic research programs will not generate a research culture in the forensic industry, but a small number of excellent research-oriented graduate programs in forensic science could help promulgate a research culture and could also produce valuable research. At present, most university-based forensic education is far more focused on training future practitioners than on training students to engage in fundamental research. We see doctoral level training in forensic science as a supplement to, rather than a substitute for, this appropriate focus.

This is not a new idea. A few institutions, both past and present, have trained doctoral students to conduct significant and foundational research. For example, at the University of California, Berkeley, Paul Kirk, and later, John Thornton, supervised a number of $\mathrm{PhD}$ dissertations on the quantitative and theoretical aspects of, among other topics, identification evaluation, ${ }^{115}$ typewriting identification, ${ }^{116}$ handwriting identification, ${ }^{117}$ and fingerprint identification. ${ }^{118}$ This was Kirk's deliberate attempt to help

115. Charles R. Kingston, Applications of Probability Theory in Criminalistics, 60 J. AM. STAT. ASS'N 70 (1965); Kwan, Q.Y., "Inference of Identity of Source," D. Crim. Dissertation, University of California, Berkeley, 1977.

116. D.A. Crown, A Statistical Evaluation of Typewriting Individuality (1969) (unpublished PhD dissertation, Univ. of Cal., Berkeley).

117. E. F. Rhodes, The Implications of Kinesthetic Factors in Forensic Handwriting Comparisons (1978) (unpublished PhD dissertation, Univ of Cal., Berkeley).

118. C.R. Kingston,, Probabilistic Analysis of Partial Fingerprint Patterns, (1964) (unpublished $\mathrm{PhD}$ dissertation, Dissertation, Univ. of Cal., Berkeley); D.A. Stoney, A 
generate fundamental, theoretical research ${ }^{119}$. Research from other early forensic science programs, such as Michigan State University under Ralph Turner, also contributed significantly to the literature, even though such programs did not offer doctoral-level training. ${ }^{120}$ Several strong European examples exist as well, both historically and at present. ${ }^{121}$

For the most part, however, there has been a disjunction between academic research and the forensic laboratory. Forensic laboratories in the United States were, from their outset, framed as arms of law enforcement and embedded within a different system of values from academia:

Without a doubt, the laboratory, as it exists in the United States, is an appendage of a quasi-military operation of an enforcement agency. As in the military, the laboratory technician in the quasimilitary operation is subordinate to the administration, which is usually not technically trained. The technician, therefore, does not have the freedom of decision nor the opportunity for research that would exist if he were a dedicated, well-trained scientist acting as a civilian in the proper framework. ${ }^{122}$

In some ways, the historical origin story of the forensic laboratory explains the divide between research values and forensic practice. The forensic laboratory, from the outset, was seen as bringing cutting edge science to enhance older investigative methods (the "needle in the haystack" method of human intelligence and shoe leather). ${ }^{123}$ The desirability of a laboratory-touted by the media as a new method of catching criminals ${ }^{124}$ - led to the hasty but enthusiastic creation of new laboratories. This perhaps contributed to the inadequate delineation of roles between traditional investigators and scientific crime-fighters, and the extent of oversight of scientists by sworn officers. In the meantime, though eager for laboratories in principle, police departments did not always appreciate what they offered, nor did they understand how to make use of

Quantitative Assessment of Fingerprint Individuality (1985) (unpublished PhD dissertation, Univ. of Cal., Berkeley).

119. See Paul L. Kirk, The Ontogeny of Criminalistics, 54 J. CRIM. L. CRIMINOlOGY \& POliCE SCI. 235 (1963).

120. R.F. Turner, Forensic Science Education-A Perspective, in 13 AM. CHEMICAL SOC'Y SYMPOSIUM SERIES 1.

121. Of particular note is the forensic science program at UNIL, in Lausanne, Switzerland.

122. C. Wilson, Crime Detection Laboratories in the United States, in FORENSIC SCIENCE: SCIENTIFIC INVESTIGATIONS IN CRIMINAL JUSTICE 96, 99-100 (J.L. Peterson ed., 1975).

123. COLIN WILSON \& DAMON WILSON, WRITTEN IN BLOOD 18-19 (2003).

124. For an instance of plus ça change plus c'est la même chose, see Max M. Houck, CSI: Reality, SCI. AM., July 2006, at 85. 
them in practice; at the extreme, they were an "incomprehensible" 125 novelty to the nonscientific police:

Some of these [law enforcement] agencies which are so eager to have a laboratory have demonstrated to the author's satisfaction that they don't even know what a laboratory is for. Even worse, they have little or no conception of the proper use of a laboratory. ${ }^{126}$

In its early days, forensic science was thus at some distance from the academy, but at the same time, it did not comfortably inhabit the universe of law enforcement either. To some extent, this interstitial set of relationships, in which forensic science is neither fish nor fowl, still affects both practice and culture.

Whatever the origin of current relationships, university-based academic programs in forensic science can usefully assist the creation of a research culture. We have already described the benefits of encouraging a small number of research-based forensic science programs. A tension often exists between disciplinary training-for example, in statistics, or psychology - and inherently interdisciplinary training, as forensic science education necessarily would be. But it need not be all or nothing. Some researchers in forensic science should come from disciplines like computer science, psychology, chemistry, biology, and statistics. But there is no reason why others might not come from university-based forensic science programs able to provide sophisticated training and access to disciplinary experts in the relevant subdisciplines. This dual-track approach to forensic research is likely to be more effective than either solely discipline-based research, or solely forensic-science-department-based research standing alone. We also recognize that the Forensic Science Educational Program Accreditation Commission (FEPAC) has to date accredited thirty undergraduate and graduate programs in North America. More importantly, FEPAC requires some degree of research at the graduate level for accreditation. ${ }^{127}$ While we applaud this requirement, we also believe

125. W. Fong, Criminalistics and the Prosecutor, in FORENSIC SCIENCE: SCIENTIFIC InVESTIGATION IN CRIMINAL JUSTICE, supra note 122, at 371 (J.L. Peterson ed., 1975).

126. Wilson, supra note 122 at 100 . See also R. PERKINS, ElEMENTS OF POLICE SCIENCE 39-40 (1942) ("In general, American detectives do not place much weight upon the application of scientific principles to the solution of the crimes which they are called upon to investigate. There is a reason for this. They place more stress on their lines of information and their acquaintance with criminals and criminal methods... ' What help,' they say, 'will science be in catching pick-pockets, bunco men, swindlers, and other types of criminal offenders?"'). Bunco is "[a] swindle perpetrated by means of card-sharping or some form of confidence trick," from "banca, a card-game similar to monte." 2 OXFORD ENGLISH DICTIONARY 654 (2d ed. 1989).

127. FEPAC states: 
that carefully delineated accreditation requirements can feed a research culture but cannot necessarily create one.

Another, perhaps more innovative, approach to integrating practical aspects into university programs is the development and implementation of a clinical forensic instruction program within the university system. David Stoney has previously drawn parallels between the current state of educational practices in modern forensic science and the state of medical practice education between 1870 and $1926 .{ }^{128}$ Stoney showed how institutions such as Johns Hopkins Medical School significantly benefited from a new innovation: the teaching hospital. Students cared for patients and discussed cases with their clinical instructors. Students learned by trying it for themselves, engaging in actual practice, rather than just watching instructors or listening to lectures. Critical thinking and concrete problem-solving ability was valued over memorization. The teaching hospital became a center of instruction, learning, and research. The teaching hospital model is similar to the atelier method of art instruction ${ }^{129}$ and both approaches have something significant to recommend to forensic science.

"Teaching forensic laboratories" would not be difficult to imagine within a university system. These laboratories could take cases from both the prosecution and defense. They could do initial analysis or perhaps could be available to reanalyze evidence. They would benefit from a lack of institutional attachment to law enforcement or structural partiality to one

Each student is required to complete an independent research project. The research project shall culminate in a thesis, or written report of publishable quality. The academic program must have written guidelines for the format of the thesis or report. In addition, the results of the work shall be presented orally in a public forum for evaluation by a committee.

The research shall be conducted in an environment conducive to research and scholarly inquiry, and shall provide the opportunity for faculty and students to contribute to the knowledge base of forensic science, including research directed at improving the practice of forensic science.

A committee of at least three individuals to include faculty, forensic practitioners and others with specialized knowledge will evaluate the project. At least one member of the committee must be external to the department housing the academic program.

ForensiC SCI. EdUC. PROGRAMS ACCREDITATION COMM'N, AM. ACAD. OF FORENSIC SCIS., ACCREDITATION STANDARDS § 5.3.2.4 (2010).

128. See David A. Stoney, A Medical Model for Criminalistics Education, 33 J. FORENSIC SCI. $1086(1988)$.

129. This method of art instruction takes its name from the French word for "artist's studio." An artist trains a small number of students in the skills and techniques associated with creating some form of representational art, starting with more basic forms and progressing through more complex methods. See R. LACK, THE AmERICAN SOCIETY OF Classical ReAlism, ON THE TRAINING OF PAINTERS: WiTH NOTES ON THE ATELIER PROGRAM (1969). 
adversarial side. ${ }^{130}$ Students, working under the care and instruction of trained practitioners, could learn from real-world cases and face a realistic but challenging array of circumstances. These teaching laboratories could also provide a place for investigating and assessing emerging research and techniques before their general dissemination to state and local forensic laboratories. These teaching laboratories could also be a useful site for conducting research on validation, as well as on bias and other human factors.

Teaching laboratories could also relieve traditional forensic science laboratories of much of the burden of training. Students emerging from a clinical instruction program would accumulate significantly more useful training and experience than current novice applicants for jobs in crime laboratories. Under the current system, successful applicants undergo lengthy training programs, some as long as one to three years. Inevitably, some trainees are poorly suited for the positions, or they discover that the profession is not for them. The costs of this wash out are high, since several years and tens of thousands of dollars have often been invested in the process before the mismatch between trainee and profession becomes clear. ${ }^{131}$ A clinical forensic instruction laboratory would reduce this inefficient hiring and training practice. Moreover, trainees who had gained experience through a training laboratory model might gain broader exposure to a richer variety of real-world circumstances and possibly even enhanced critical thinking abilities from their hands-on experiences.

\section{Improving the Culture of Forensic Science Journals}

To improve the research culture of the pattern identification sciences, some changes to the current approach to journals and publications are sorely needed. First, all forensic science journals should insist upon a fullfledged commitment to research norms. Publication in any journal that is not indexed by at least some of the major indexing services should, in a sense, not even count as publication. Peer review should be serious, blind,

130. Indeed, perhaps a procedure could be developed in which a party could, in certain circumstances, request that a court require such an impartial laboratory to analyze disputed evidence.

131. In a case study involving one laboratory, poorly designed hiring procedures led to attrition costs estimated at roughly $\$ 850,000$, and estimated lost productivity of nearly $\$ 5$ million (because of the loss of sixteen employees). These cost estimates did not include the costs associated with recruiting, selection, or training. See W. Mark Dale \& Wendy B. Becker, A Case Study of Forensic Scientist Turnover, FORENSIC SCI. COMM. (July 2004), http://www2.fbi.gov/hq/lab/fsc/backissu/july2004/research/2004_03_research04.htm. 
and carried out by individuals well qualified to assess the research merits of any given article. While non-research-oriented practitioners can play a valuable role in peer review as well, evaluations by those with the necessary qualification to assess the merits and execution of any given study should dominate the criteria for acceptance. It should also go without saying that concerns about whether a given set of findings comports with practitioners' (or researchers') expectations and desires should not affect publishing decisions. To be sure, some findings are more interesting or surprising than others, and this may legitimately affect evaluations of a given article. But the fact that a research result might alienate or irritate practitioners ought not to affect publication decisions.

The pattern identification disciplines would also benefit from a genuine flagship journal that crosses between forensic science itself and broader research paradigms. Perhaps the JFS, which is already a legitimate and respected research vehicle, can play this role. However, the pattern disciplines make up a small part of JFS publications, and the JFS does not especially focus on the intersections of forensic science with other disciplines. Whether a new flagship journal focusing on pattern evidence would be feasible is a difficult question. In an ideal world, such a journal would link in equal quantities to other forensic sciences and also to other academic fields, like statistics, cognitive psychology, and electrical and computer engineering. How to create such a flagship journal is not obvious, but one place to start would be with a high-powered and interdisciplinary editorial board that reaches broadly into ancillary disciplines as well as including leading members of the forensic science research community.

\section{Using Scientific Standards to Guide Casework}

Another set of suggestions focuses on efforts to use conventional scientific standards to guide casework. One key example is "sequential unmasking." ${ }^{132}$ Analysts should have access to all the domain-relevant information they need to conduct their inquiry, but they should be shielded from domain-irrelevant matters unless or until those matters affect the analysis. A fingerprint examiner, for example, likely does need to know the surface from which a print was lifted. A fingerprint examiner does not need to know, however, about the suspect's confession or his three prior

132. See Dan E. Krane et al., Sequential Unmasking: A Means of Minimizing Observer Effects in Forensic DNA Interpretation, 53 J. FORENSIC SCI. 1006 (2008). The basic idea of sequential unmasking (without the use of that label) was set out in Risinger et al., supra note 49, at 50-51. 
convictions for similar crimes. A document examiner cannot escape seeing the content of the document being analyzed; however, she need not be told broader aspects of the prosecution's theory of the case.

Sequential unmasking creates protocols that protect examiners from these kinds of biasing information. ${ }^{133}$ From a research culture perspective, sequential unmasking offers two significant benefits. First, it protects examiners from materials and knowledge that might otherwise have a biasing effect on their evaluation. ${ }^{134}$ The enormous literature on bias and cognition suggests the value of providing such a shield. ${ }^{135}$

Sequential unmasking has another benefit as well. Because it requires practitioners to think carefully about what information is domain-relevant and what is not, and why, sequential unmasking also encourages precisely the kind of careful attention to the relationship between evidence and warrant that a research culture demands. The very process of thinking hard and justifying the inclusion or exclusion of certain kinds of information from an examiner's purview will be a meaningful step toward the instantiation of a research culture.

Implementing blind proficiency tests in the stream of casework would be another way to make casework better comport with scientific principles for the production of knowledge. Controlled, double-blind studies are the gold standard in medicine. ${ }^{136}$ In a double-blind study, practitioners and patients do know that they are participating in a research study, but their potential interpretive biases and expectation effects are reduced because they do not know if they are receiving the medication being tested or a placebo. Similarly, proficiency test subjects (and those administering the test) ideally ought not to know when they are pursuing ordinary casework and when they are undergoing a proficiency test.

133. Krane et al., supra note 132. To be sure, sequential unmasking may also increase costs by requiring an additional layer of personnel to assess what information is domain-relevant and to ensure that non-domain-relevant information is stripped from the materials the examiner receives. But given the strong evidence in other fields of the biasing effects of context information, the onus arguably ought to be on the forensic practitioner community to show why these costs are not worth incurring.

134. Dror \& Rosenthal, supra note 32, at 902-03; Dror \& Charlton, supra note 32, at 612; Risinger et al., supra note 49 , at 45 . Note that domain-relevant information may also generate bias, for example, when a DNA examiner looks at a mixture already knowing the suspect's profile.

135. For an overview of some of this literature and its highlights, see generally Risinger et al., supra note 49.

136. See, e.g., John Concato, et al., Randomized, Controlled Trials, Observational Studies, and the Hierarchy of Research Designs, 342 NEW. ENG. J. MED. 1887 (2000); Henry Sacks et al., Randomized Versus Historical Controls for Clinical Trials, 72 AM. J. MED. 233 (1982). 
Improving documentation practices in order to increase transparency is another step to incorporate scientific standards. While the particular degree of documentation may appropriately vary with the complexity of the comparison, documentation should be both thorough and transparent. If a fingerprint examiner, for example, finds additional minutiae on a latent print after beginning the comparison process, this back-and-forth reasoning should be clearly noted. Similarly, an examiner should indicate the degree of confidence (for example, high, medium, low) in the existence of minutiae or striations or handwriting features in the disputed exemplar in advance of undertaking any comparison. While careful documentation is no substitute for the empirical research needed to establish the power and the limits of various techniques, it can usefully clarify an examiner's reasoning process and the basis for any conclusions, and may offer some protections from the potential biasing effect of the comparison process. ${ }^{137}$

\section{E. Enhancing the "Science" in the Scientific Working Groups (SWGs)}

Guidelines and standards for forensic practice in a great many forensic disciplines are developed and recommended by entities known as Scientific Working Groups (SWGs), funded by the Department of Justice. Most of these working groups, which have emerged over the past twenty years, operate under the auspices of the FBI laboratory. They were designed to develop best practices, create appropriate technical standards, and improve communications both within and among various forensic disciplines. ${ }^{138}$ Scientific Working Groups exist for firearms and toolmarks (SWGGUN), friction ridge analysis study and technology (SWGFAST), imaging technology (SWGIT), DNA (SWGDAM), shoeprint and tire tread evidence (SWGTREAD), drug analysis (SWGDRUG), as well as for a number of other forensic disciplines. These organizations have provided important venues for consensus building, policy development, and knowledge dissemination.

However, despite the scientific label in the name of the working groups, SWGs have a rather tenuous relationship with research science.

137. Glenn Langenburg \& Christophe Champod, The GYRO System-A Recommended Approach to More Transparent Documentation (July 9, 2010) (draft), available at http://projects.nfstc.org/ipes/presentations/Langenburg_GYRO-System.pdf. See generally, Interpretation Chapter, in NIST/NIJ Working Group Report (forthcoming 2011).

138. For basic information about the SWGs, see Scientific Working Groups, FED. BUREAU OF INVESTIGATION, http://www.fbi.gov/about-us/lab/swgs (last visited Dec. 30, 2010). Several SWGs operate from locations other than the FBI. SWGRUG operates out of the DEA, and SWGSTAIN operates out of the Midwest Forensic Resource Center. 
Indeed, some of them previously went by other names. For example, SWGDAM, the FBI's DNA advisory group, used to be known as TWGDM, the technical working group on DNA analysis and methods.

What should a scientific working group worthy of the name look like? Certainly a legitimate scientific working group would necessarily include practitioners who could inform the group about best and current practices in the discipline as well as practical constraints that operate within that area. These participants would be critical to the proper grounding and anchoring of a forensic science working group. However, these nonresearcher practitioners should make up only a minority of the group's total members. The major focus of SWGs should be to ensure that all recommendations for methods and practices are grounded in research and validated. When insufficient research exists, SWGs should determine what research is most critical to assess standards or best practices. Given these purposes, the bulk of the membership in scientific working groups should be scientists who have a relevant research background. Indeed, some members should be scientists outside the forensic discipline of the SWG and some should come from outside of forensic science entirely. These members will offer fresh perspectives and help avoid the danger of excessive buy-in to current practices simply because they are both known and familiar. The workings of the SWG would thus be driven by scientists and scientific considerations along with thoughtful input from the practitioners who would contribute to the formulation and help to operationalize the SWG's recommendations. If SWGs were organized in this fashion, they would help create and perpetuate a research culture, and ensure that forensic science fields use recommended methods and processes based on scientific principles and informed by scientific research.

While the membership of the current SWGs varies, most of them are substantially more practitioner-led than what we have just described. The working group on friction ridge analysis study and technology (SWGFAST), for example, is one of the stronger SWGs. Several current members have serious and significant research interests. But they form only a small minority of the total membership. On the one hand, given the paucity of research opportunities and the structure of forensic science, this limited proportion of research-oriented members is only to be expected. But in a research culture one would expect - and insist - that the standardsetting, guideline-creating, policy body for any given field be structured so as to ensure that its decisions are based upon data and research, not simply the result of a two-thirds vote from a practitioner-dominated working 
group. ${ }^{139}$ To be sure, practitioner-led SWGs may often reach appropriate, thoughtful, and perhaps even research-based conclusions, but they also risk being guided by and influenced by populist practitioner pressures. To be worthy of their name, SWGs need to make certain that scientific findings and an appreciation for a research culture drive decisions.

The National Institute of Standards and Technology (NIST) may take over the SWGs in the near future; we hope that such a move will incorporate a major restructuring of how the SWGs operate. If such a move is merely a change in their funding source from the DOJ to NIST without significant structural changes, SWGs may be useful as sounding boards for leading practitioners, but they will continue to have little to do with a research culture.

\section{F. Access to Data}

Another needed dimension for a robust research culture is access to data and test subjects. Participation in the research enterprise must obviously be balanced against a laboratory's other needs, and a laboratory may be unable to participate in every research project asked of it. However, access to data-exemplars and databases-should not be limited to practitioners at a given laboratory. With appropriate precautions for protecting confidentiality and the necessary input of Institutional Review Boards, forensic laboratories, as well as institutions like the FBI and state and federal criminal justice authorities, should make data available to qualified researchers to the maximum extent possible. ${ }^{140}$

To create incentives for providing this access, participating as research subjects ought to become an accreditation requirement for forensic labs. Just as many law schools have implemented pro bono requirements for students, the American Society of Crime Laboratory Directors Laboratory Accreditation Board (ASCLD-LAB) should require that every laboratory devote a given number of hours to participation in research. The details of how to structure such a requirement could be worked out in a variety of

139. For SWGFAST's bylaws, as an example, see Bylaws, SCIENTIFIC WORKING GROUP ON Friction RIDGE ANALYSIS, STUDY \& TECH. (Sept. 15, 2009), http://www.swgfast.org/Resources/Bylaws_3.2-Corrected.pdf.

140. This has been an ongoing issue in DNA analysis as well. For example, researchers have unsuccessfully endeavored to access anonymized DNA profiles from the United States National DNA Index system, controlled by the FBI. See D. E. Krane et al., Time for DNA Disclosure, 326 SCIENCE 1631 (2009). Yet, some researchers have had access to databases for other countries. See David H. Kaye, Trawling DNA Databases for Partial Matches: What Is the FBI Afraid of?, 19 CORNELL J. L. \& PUB. POL'Y 145, 161-65 (2009). 
ways. Perhaps every employee should be allowed a modest number of paid work hours for participation as a "test subject" in the research study of her choice; or perhaps laboratories should create more structured systems for participation. Whatever the details, the point is to create workable mechanisms to encourage research participation by sometimes wary laboratories. To be clear, laboratories themselves would not necessarily spearhead these research projects. Rather, analysts would be made available as test subjects, consulting on the feasibility of certain research endeavors, providing feedback on what research questions would have practical payoff for laboratories, and creating partnerships with researchers both from within and from outside the forensic sciences.

\section{G. Managing the Tension Between an Adversarial Culture and a Research Culture}

The fact that the pattern identification fields and other forensic sciences are embedded within the legal system has made it difficult for a research culture to flourish. Numerous commentators (and the NAS Report) have criticized the institutional connections between the police, the prosecutors, and the crime laboratories. Indeed, the NAS Report, like some scholarship that preceded it, explicitly calls for making crime laboratories independent of these other domains. ${ }^{141}$

Clearly structural risks of both bias and partisanship stem from the institutional location of crime laboratories. Several scandals have illustrated the dangers raised by forensic scientists who may feel pressured to provide prosecutors with what they are seeking. ${ }^{142}$ Partisanship is a serious and long-recognized danger for all kinds of expert witnesses, ${ }^{143}$ and operating as part of the institutional apparatus of law enforcement may make practitioners unconsciously partisan. ${ }^{144}$ Additionally, the strong institutional links to police investigators may compromise efforts to protect examiners from access to unnecessary, and potentially biasing, contextual

141. NAS REPORT, supra note 8, at 183-84; Paul C. Giannelli, The Abuse of Scientific Evidence in Criminal Cases: The Need for Independent Crime Laboratories, 4 VA. J. SOC. POL'Y \& L. 439, 470-73 (1997); Roger Koppl, How to Improve Forensic Science, 20 EUR. J. L. \& ECON. 255, 258 (2005).

142. See, e.g., Locke \& Neff, supra note 5.

143. See, e.g., Samuel R. Gross, Expert Evidence, 1991 WIS. L. REV. 1113; Jennifer L. Mnookin, Expert Evidence, Partisanship, and Epistemic Competence, 73 BROOK. L. REV. 1009 (2008).

144. David E. Bernstein, Expert Witnesses, Adversarial Bias, and the (Partial) Failure of the Daubert Revolution, 93 IOWA L. REV. 451, 456 (2008). 
information about the case. To be sure, there may also be benefits from the current institutional location, ranging from possible efficiency gains from police authority over forensic science, to motivational gains for forensic scientists who may benefit psychologically from being part of law enforcement. And of course, any institutional location has its own set of costs and benefits that would need to be compared to the current set. ${ }^{145}$

Most, but not all, of us believe that institutional separation of laboratories from the law enforcement apparatus would be tremendously beneficial for reducing the dangers of partisanship and fostering a research culture. However, most, but not all, of us also believe that even if this is indeed a worthy and highly desirable goal, it is also unlikely to be realized in the near future. One small but constructive step toward creating at least a modicum of psychological distance between laboratories and the implicit (or, sometimes explicit) pressures from law enforcement would be a requirement that all laboratories perform a certain quantity of defense-side work, enabling analysts to gain experience in a different role vis-à-vis the adversary system. ${ }^{146}$

However, the problematic dynamics of adverarialism and their potentially pathological effects on a research culture go beyond the sometimes-too-cozy prosecutor-police-forensic-science relationship. The dynamics of the courtroom and of the adversarial process itself can create significant incentives for analysts to resist the collection of information or the production of data that might assist their adversary or weaken their own credibility. If any documented error is likely to haunt an examiner on every subsequent cross-examination, there may be little motivation to identify or audit mistakes. If difficult proficiency tests would potentially provide extensive fodder for defense attorneys, why would examiners risk shooting themselves (or the prosecutors with whom they work) in the foot by attempting to determine the limits to their own abilities?

We do not have any simple fixes for this set of structural difficulties, but we offer two suggestions. First, we would suggest that laboratories

145. See Dror, supra note 25, at 101-02.

146. At present, not only do most state laboratories not regularly conduct testing for the defense, but policies about whether state laboratory workers can consult for the defense in other jurisdictions vary. One recent controversy in Minnesota illustrates the depth of adversarial norms. When a medical examiner consulted for the defense in a case in another county, the prosecutor in her home county complained to her boss, causing the medical examiner to fear for her job. While the prosecutor later apologized and was reprimanded for his behavior, the incident captures the conceptual partisanship frequently seen in the field-the notion that state forensic science workers are tied to the prosecution. See Joy Powell, Dakota County Prosecutor Reprimanded by State Board, MinNEAPOLIS-ST. PAUl STAR TRIBUNE, May 19, 2009. 
consider extending something akin to Brady duties to examiners themselves. Under Brady v. Maryland, ${ }^{147}$ prosecutors have an ethical duty to report exculpatory evidence to defense attorneys. Brady has already been extended to information in the possession of agents of the prosecution such as the police, ${ }^{148}$ and there is no reason that this should not apply to forensic scientists. While a forensic scientist may have a legal duty to disclose exculpatory evidence to a prosecutor, courts have not held Brady duties to extend directly from the forensic scientist or police to the defense. What would be the consequences of an ethical obligation of forensic scientists to disclose directly to the defense any exculpatory findings or any interlaboratory disagreement regarding conclusion or interpretation? Perhaps more robust reporting requirements, in which an analyst routinely discloses any interpretive disagreement within her laboratory report, would be a simpler means to achieve a similar goal. The purpose of either a disclosure requirement or enhanced reporting norms is in part to increase the degree of perceived and subjectively felt independence from law enforcement, even if no formal institutional realignment takes place. At a minimum, a research culture should mean clear and robust expectations about transparency and documentation: Reports should carefully detail steps taken, findings reached, and internal disagreement (if any) about the results or the interpretation.

A second idea worth considering is whether there ought to be a protective evidentiary privilege that attaches to self-critical investigation and analysis in at least some circumstances. This presents an extremely difficult question of balancing competing goals. Creating a privilege that protects a laboratory from having to disclose what it learns through the investigation of an error may lead to much better error investigation that may in turn reduce future errors. But in the particular case, this benefit would come at the expense of keeping highly relevant, potentially exculpatory material from defendants. Although some courts have recognized a self-critical analysis privilege in the medical peer review context (which faces structurally similar issues, though typically in a civil rather than criminal setting), it is quite unlikely that courts would extend it to the criminal domain, in significant part because of the criminal defendant's constitutional due process right to exculpatory information.

Nonetheless, it may be worth considering whether there are any feasible mechanisms through which defendants' legitimate (and, in some

147. 373 U.S. 83, 87 (1963).

148. See, e.g., Kyles v. Whitley, 514 U.S. 419 (1995). 
instances, constitutionally mandated) need for information could appropriately be balanced against efforts to promote self-analysis and research. It is difficult to imagine a privilege that would protect a laboratory from the disclosure of an error in actual casework. But what if a laboratory wanted to test its examiners' proficiency on difficult and close nonmatches? Should it be able to protect itself from having to report their results? Should a researcher be protected from having to identify the laboratories that participated in a study? Or which individuals achieved what results? To what extent should some kind of research privilege protect both researchers and laboratories in order to remove one major impediment to cooperation, when the results do not directly implicate any particular case or defendant?

Finally, we believe the fear that admitting imperfections might significantly harm jurors' understanding and appreciation of the pattern identification sciences may be largely chimerical. It is not clear that jurors would substantially discount conclusions from forensic science examiners even if they were presented with information quantifying error rates greater than zero; even if they knew that this particular examiner had made an occasional mistake on proficiency tests; and even if they knew that a socalled match did not necessarily mean that every other human being (or bullet, or tool) in the world could be excluded as a potential source. Certainly mitochondrial DNA evidence-which cannot ever, standing alone, individualize because maternal relatives share the same mitochondrial DNA—can significantly contribute to a successful prosecution. Particularly in those cases in which the pattern identification evidence was combined with other probative evidence suggesting guilt, it is hardly obvious that these caveats with regard to the pattern identification evidence would have any significant impact on juror reasoning. ${ }^{149}$ And in

149. This is, of course, an empirical question. We can, however, make some guesses from the literature on how jurors weigh expert testimony. See, e.g., Valerie P. Hans et al., Science in the Jury Box: Jurors' Comprehension of Mitochondrial DNA Evidence, LAW \& HUM. BEHAV. (forthcoming 2010); David H. Kaye et al., Statistics in the Jury Box: How Jurors Respond to Mitochondrial DNA Probabilities, 4 J. EMPIRICAL LEGAL STUD. 797 (2007); Jonathan J. Koehler et al., The Random Match Probability in DNA Evidence: Irrelevant and Prejudicial?, 35 JURIMETRICS 201 (1995); Dawn McQuiston-Surrett \& Michael J. Saks, Communicating Opinion Evidence in the Forensic Identification Sciences: Accuracy and Impact, 59 Hastings L.J. 1159 (2008); Dawn McQuiston-Surrett \& Michael J. Saks, The Testimony of Forensic Identification Science: What Expert Witnesses Say and What Factfinders Hear, 33 LAW \& HuM. BEHAV. 436 (2009); Dale A. Nance \& Scott B. Morris, An Empirical Assessment of Presentation Formats for Trace Evidence With a Relatively Large and Quantifiable Random Match Probability, 42 JuRIMETRICS J. 403 (2002); Dale A. Nance \& Scott B. Morris, Juror Understanding of DNA Evidence: An Empirical Assessment of Presentation Formats for Trace Evidence With a Relatively Small Random-Match Probability, 34 J. LEGAL STUD. 
those rare cases where the pattern identification evidence stands largely alone, perhaps a greater degree of skepticism would be epistemologically warranted.

\section{CONCLUSION}

Our purpose in writing this Article has been to bring together a group of practitioners and academics who have all spent time thinking hard about forensic science, to see if we could find consensus about how to improve the field. Although many of us inhabit overlapping intellectual and professional circles, we did not all know each other beforehand, and we come from a variety of different intellectual traditions and locations. This project therefore began as something of an experiment. Its origin was at a conference held at UCLA in February 2009, on the one-year anniversary of the release of the NAS Report. After the public symposium, sponsored by the UCLA School of Law's Program on Understanding Law, Science, and Evidence (PULSE), this group of coauthors gathered for an intense, daylong brainstorming session.

As we discussed, outlined, and argued, we discovered that our views had more in common than one might have expected. ${ }^{150}$ Indeed, we found that in many important respects, our views of what forensic science most needed significantly converged.

We all believe that the NAS Report got far more right than it got wrong. We all believe that many forms of forensic science today stand on an insufficiently developed empirical research foundation. We all believe that forensic science does not yet have a well-developed research culture. These disciplines, in our view, need to increase their commitment to empirical evidence as the basis for their claims. Sound research, rather than experience and training, must become the central method by which assertions are justified. While there can indeed be a legitimate role for experience-based claims of knowledge, such claims need to be both put forward with appropriate epistemic modesty and assessed through feedback mechanisms. The answer to the question "How well can you do what you

395 (2005); Jason Schklar \& Shari Seidman Diamond, Juror Reactions to DNA Evidence: Errors and Expectancies, 23 LAW \& HUM. BEHAV. 159 (1999); Jonathan J. Koehler, If the Shoe Fits They Might Acquit: The Perceived Value of Shoeprint Testimony (Sept. 13, 2010) (unpublished manuscript, on file with UCLA Law Review).

150. Jerry Kang also participated in our day-long session and used MindManager to "map" our conversation in real time. Both our brainstorming process and the drafting of this Article were greatly assisted by his tremendous mind-mapping skill. 
say you can do?" is more properly answered by blind proficiency tests than by reference to experience or training. The forensic sciences need to increase their commitment to transparency along a variety of dimensionsfrom increasing the documentation provided in complex cases; to more readily sharing data with researchers; to increasing access to protocols and standard procedures; to acknowledging and learning from errors. In addition, the pattern and impression fields, as well as other forms of forensic science, need to develop and sustain an ongoing critical and reflective stance, in which yesterday's truths can be revisited tomorrow.

We have offered a number of suggestions for ways to develop and improve a research culture in these fields, but we are frankly more confident in our diagnosis than in our specific suggestions for possible cures. We are, however, unanimous in hoping and believing that this is a rather special historical moment, a time when cultural change in forensic science-even perhaps, a genuine "paradigm shift" the very fact of our writing this Article together provides a small piece of evidence that this change has already begun.

151. Michael J. Saks \& Jonathan J. Koehler, The Coming Paradigm Shift in Forensic Identification Science 309 SCIENCE 892, 895 ("[W]e envision a paradigm shift in the traditional forensic identification sciences in which untested assumptions and semi-informed guesswork are replaced by a sound scientific foundation and justifiable protocols."). For the classic discussion of paradigm shifts in science, see THOMAS KUHN, THE STRUCTURE OF SCIENTIFIC REVOLUTIONS (2d ed. 1970). 